\title{
THE
}

$1-15-2021$

\section{Behavioral and Demographic Responses of Mule Deer to Energy Development on Winter Range}

Joseph M. Northrup

Charles R. Anderson Jr

Brian D. Gerber

University of Rhode Island, bgerber@uri.edu

George Wittemyer

Follow this and additional works at: https://digitalcommons.uri.edu/nrs_facpubs

The University of Rhode Island Faculty have made this article openly available.

Please let us know how Open Access to this research benefits you.

This is a pre-publication author manuscript of the final, published article.

Terms of Use

This article is made available under the terms and conditions applicable towards Open Access Policy Articles, as set forth in our Terms of Use.

Citation/Publisher Attribution

Northrup, J.M., Anderson, C.R., Jr., Gerber, B.D. and Wittemyer, G. (2021), Behavioral and Demographic Responses of Mule Deer to Energy Development on Winter Range. Wild. Mon., 208: 1-37. https://doi.org/ 10.1002/wmon.1060

This Article is brought to you for free and open access by the Natural Resources Science at DigitalCommons@URI. It has been accepted for inclusion in Natural Resources Science Faculty Publications by an authorized administrator of DigitalCommons@URI. For more information, please contact digitalcommons-group@uri.edu. 
November 10, 2020

Joseph M. Northrup

2140 East Bank Drive

Peterborough, ON K9L 1Z8 Canada

joe.northrup@gmail.com

RH: Northrup et al. - Behavior and Demography of Mule Deer

Behavioral and Demographic Responses of Mule Deer to Energy Development on Winter

9

\section{Range}

JOSEPH M. NORTHRUP, ${ }^{1,2}$ Department of Fish, Wildlife and Conservation Biology, Colorado State University, 1474 Campus Delivery, Fort Collins, CO 80523, USA; Wildlife Research and Monitoring Section, Ontario Ministry of Natural Resources and Forestry, 2140 East Bank Drive, Peterborough, ON K9L 1Z8, Canada

CHARLES R. ANDERSON JR, ${ }^{2}$ Mammals Research Section, Colorado Parks and Wildlife, 317 W Prospect Road, Fort Collins, CO 80526, USA

BRIAN D. GERBER, Department of Natural Resources Science, University of Rhode Island, 1 Greenhouse Road, Kingston, RI 02881-2018, USA

GEORGE WITTEMYER, Department of Fish, Wildlife and Conservation Biology, Colorado State University, 1474 Campus Delivery, Fort Collins, CO 80523, USA

ABSTRACT Anthropogenic habitat modification is a major driver of global biodiversity loss. In North America, one of the primary sources of habitat modification over the last 2 decades has been exploration for and production of oil and natural gas (hydrocarbon development), which has led to demographic and behavioral impacts to numerous wildlife species. Developing effective

\footnotetext{
${ }^{1}$ Email: joe.northrup@gmail.com

${ }^{2}$ Authors contributed equally to this work
} 
measures to mitigate these impacts has become a critical task for wildlife managers and conservation practitioners. However, this task has been hindered by the difficulties involved in identifying and isolating factors driving population responses. Current research on responses of wildlife to development predominantly quantifies behavior, but it is not always clear how these responses scale to demography and population dynamics. Concomitant assessments of behavior and population-level processes are needed to gain the mechanistic understanding required to develop effective mitigation approaches. We simultaneously assessed the demographic and behavioral responses of a mule deer population to natural gas development on winter range in the Piceance Basin of Colorado, USA, from 2008 to 2015. Notably, this was the period when development declined from high levels of active drilling to only production phase activity (i.e., no drilling). We focused our data collection on 2 contiguous mule deer winter range study areas that experienced starkly different levels of hydrocarbon development within the Piceance Basin.

We assessed mule deer behavioral responses to a range of development features with varying levels of associated human activity by examining habitat selection patterns of nearly 400 individual adult female mule deer. Concurrently, we assessed the demographic and physiological effects of natural gas development by comparing annual adult female and overwinter fawn (6month-old animals) survival, December fawn mass, adult female late and early winter body fat, age, pregnancy rates, fetal counts, and lactation rates in December between the 2 study areas. Strong differences in habitat selection between the 2 study areas were apparent. Deer in the lessdeveloped study area avoided development during the day and night, and selected habitat presumed to be used for foraging. Deer in the heavily developed study area selected habitat presumed to be used for thermal and security cover to a greater degree. Deer faced with higher densities of development avoided areas with more well pads during the day and responded 
neutrally or selected for these areas at night. Deer in both study areas showed a strong reduction

49 in use of areas around well pads that were being drilled, which is the phase of energy

50 development associated with the greatest amount of human presence, vehicle traffic, noise, and

51 artificial light. Despite divergent habitat selection patterns, we found no effects of development

52 on individual condition or reproduction and found no differences in any of the physiological or

53 vital rate parameters measured at the population level. However, deer density and annual

54 increases in density were higher in the low-development area. Thus, the recorded behavioral

55 alterations did not appear to be associated with demographic or physiological costs measured at

56 the individual level, possibly because populations are below winter range carrying capacity.

57 Differences in population density between the 2 areas may be a result of a population decline

58 prior to our study (when development was initiated) or area-specific differences in habitat

59 quality, juvenile dispersal, or neonatal or juvenile survival; however, we lack the required data to

60 contrast evidence for these mechanisms.

Given our results, it appears that deer can adjust to relatively high densities of well pads

62 in the production phase (the period with markedly lower human activity on the landscape),

63 provided there is sufficient vegetative and topographic cover afforded to them and populations

64 are below carrying capacity. The strong reaction to wells in the drilling phase of development

65 suggests mitigation efforts should focus on this activity and stage of development. Many of the

66 wells in this area were directionally drilled from multiple-well pads, leading to a reduced

67 footprint of disturbance, but were still related to strong behavioral responses. Our results also

68 indicate the likely value of mitigation efforts focusing on reducing human activity (i.e., vehicle

69 traffic, light, and noise). In combination, these findings indicate that attention should be paid to

70 the spatial configuration of the final development footprint to ensure adequate cover. In our 
71 study system, minimizing the road network through landscape-level development planning

72 would be valuable (i.e., exploring a maximum road density criteria). Lastly, our study highlights

73 the importance of concomitant assessments of behavior and demography to provide a

74 comprehensive understanding of how wildlife respond to habitat modification.

76 KEY WORDS Bayesian hierarchical model, Colorado, global positioning system radio-collar,

77 mark-resight, natural gas development, Odocoileus hemionus, resource selection function, risk-

78 disturbance hypothesis, spatial ecology, survival.

\section{RÈSUMÈN}

81 Les modifications anthropogéniques de l'habitat sont une source majeure de la perte de biodiversité. En

82 Amérique du Nord, l'une des sources importantes de modification de l'habitat durant les deux dernières

83 décennies est reliée à l'exploration et à la production d'huile et de gaz naturel (développements reliés

84 aux hydrocarbures). Ces développements ont causé des impacts démographiques et comportementaux

85 pour de nombreuses espèces fauniques. Développer des mesures efficaces afin de réduire ces impacts

86 est devenu une tâche importante des gestionnaires de la faune et des conservationnistes. Cependant,

87 cette tâche a été compliquée par les difficultés associées à l'identification des facteurs influençant les

88 réponses de la population aux développements. Les recherches portant sur les réponses de la faune aux

89 développements quantifient principalement le comportement, mais il n'est pas toujours facile de

90 comprendre comment ces réponses sont reliées à la démographie et à la dynamique des populations.

91 Une évaluation concomitante du comportement et des processus de la population sont requis afin

92 d'obtenir une compréhension mécanistique permettant de développer des mesures de mitigation

93 appropriées. Nous avons évalué simultanément les réponses démographiques et comportementales

94 d'une population de cerf mulet sur leur aire d'hivernage, associées au développement relié au gaz 
naturel dans le bassin Piceance du Colorado, USA, entre 2008 et 2015. Ceci correspondait à la période

96 où le niveau de développement a fluctué de façon importante, entre une phase de forage active et une

97 phase de production (sans forage). Nous avons concentré notre collection de données sur deux aires d'hivernage adjacentes qui ont subi des niveaux différents de développement reliés aux hydrocarbures à

99 l'intérieur du bassin Piceance.

Nous avons évalué la réponse comportementale des cerfs mulets aux attributs reliés au

101 développement avec des niveaux variés d'activités humaines en examinant la sélection d'habitat de près 102 de 400 femelles cerfs mulets. Nous avons aussi évalué l'effet des développements reliés au gaz naturel 103 sur la démographie et la physiologie en comparant la survie annuelle des femelles adultes et la survie 104 hivernale des faons (âgés de 6 mois), les réserves de gras des femelles au début et à la fin de l'hiver, 105 l'âge, le taux de gestation et le taux de lactation en décembre entre les deux aires d'études. Des différences majeures au niveau de la sélection d'habitat ont été observées entre les deux aires d'études.

107 Les cerfs habitant l'aire d'étude moins développée évitaient les zones développées durant le jour et la 108 nuit et sélectionnaient des habitats afin de s'alimenter. Les cerfs habitant l'aire d'étude plus développée 109 sélectionnaient plus fortement des habitats à des fins de sécurité et de couvert thermal. Les cerfs faisant 110 face à une plus grande densité de développement évitaient les endroits avec une plus grande densité de 111 puits durant le jour alors qu'ils n'évitaient pas ou sélectionnaient ces endroits durant la nuit. Les cerfs 112 habitant les deux aires d'études montraient une réduction importante de l'utilisation des puits durant 113 leur forage, ce qui correspondait à la phase de développement avec la plus grande présence humaine, 114 circulation automobile, bruit, et lumière artificielle. Malgré des patrons de sélection d’habitat 115 divergents, nous n'avons pas détecté un effet des développements sur la condition ou la reproduction et 116 nous n'avons pas trouvé de différence chez les taux vitaux ou physiologiques mesurés au niveau de la 117 population. Cependant, la densité de cerfs et le taux de changement annuel dans la densité étaient 118 supérieurs dans l'aire d'étude moins développée. Les changements comportementaux mesurés ne 
semblaient donc pas être associés avec des coûts démographiques ou physiologiques au niveau

120 individuel, possiblement parce que les populations étaient sous la capacité biotique de l’aire

121 d'hivernage. Les différences entre les densités de population entre les deux aires d'études sont peut-

122 être dû à un déclin de la population précédant notre étude (lorsque le développement démarrait) ou à

123 des différences au niveau de la qualité de l'habitat, du dispersement ou de la survie des nouveau-nés ou

124 des juvéniles. Cependant, nous manquons les données requises pour contraster ces mécanismes.

Selon nos résultats, il apparait que les cerfs mulets peuvent s'adapter à une densité élevée de

126 puits durant la phase de production (la période avec moins d'activités humaines) si la quantité de

127 protection offerte par la végétation et la topographie est suffisante et si la population est sous la

128 capacité biotique. La forte réponse aux puits durant la période de forage indique que les mesures de

129 mitigation devraient prioriser ces activités et ce stade de développement. Plusieurs des puits de la

130 région étaient percés directionnellement à partir d’un même endroit, entraînant une réduction de

131 l'emprise, mais ils entrainaient néanmoins une réponse comportementale des cerfs. Nos résultats

132 démontrent aussi l'importance potentielle de mesures de mitigation tentant de réduire le niveau

133 d'activité humaine (i.e.la circulation automobile, la lumière et le bruit). Nos résultats soulignent

134 l'importance de porter attention à la configuration spatiale du développement afin d'assurer un niveau

135 de couvert suffisant. Dans notre système, minimiser le réseau des routes en utilisant une planification

136 au niveau du paysage pourrait être utile (i.e. explorer un critère maximum pour la densité de route).

137 Dernièrement, notre étude a démontré l'importance d'évaluer en même temps le comportement et la

138 démographie afin de procurer une compréhension globale de la réponse de la faune aux modifications 139 de l'habitat. 


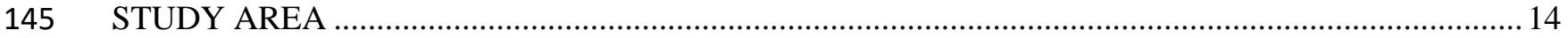

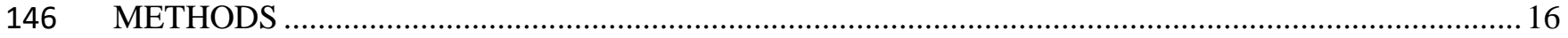

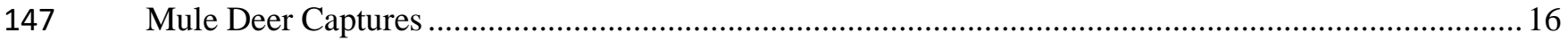

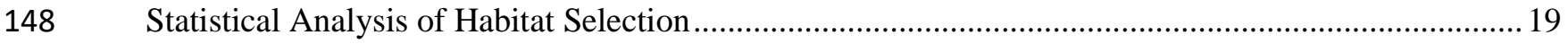

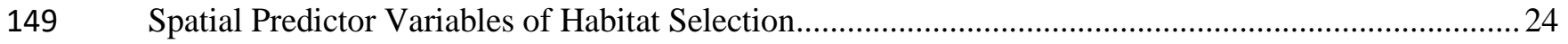

$150 \quad$ Field and Statistical Methods for Demographic Analyses .............................................................28

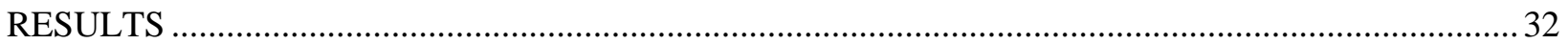

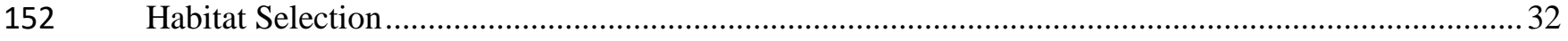

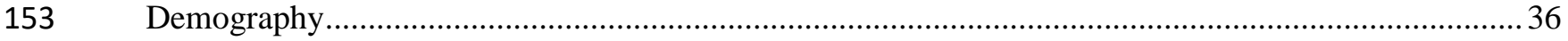

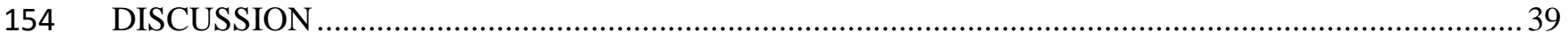

$155 \quad$ Mule Deer Behavior and Natural Gas Development …................................................................ 42

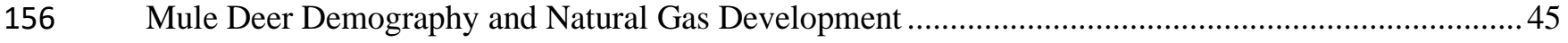

157 The Use of Habitat Selection Analyses to Assess Effects of Human Disturbance ...............................53

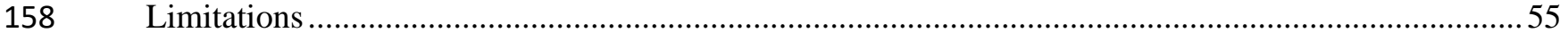

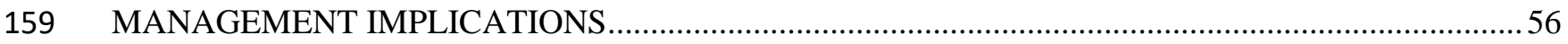

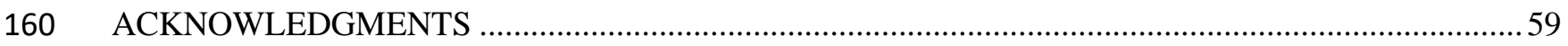

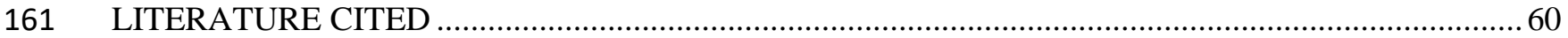

162

INTRODUCTION

164 Land-use change and associated human activities have profound effects on ecological processes 165 (Vitousek et al. 1997, Foley et al. 2005, Haberl et al. 2007). These effects include disrupting 166 long-distance animal migrations (Harris et al. 2009), altering animal behavior (Tuomainen and 167 Candolin 2011), facilitating the introduction of nonnative species (Hansen and Clevenger 2005), 168 and driving declines of local populations and global biodiversity (Wilcove et al. 1998, Sala et al. 1692000 , Gibson et al. 2013). In the coming decades, land-use change will continue to alter natural 
170 systems, modifying thousands of square kilometers of land (Li et al. 2017) with negative

171 consequences for some species and ecosystems (Lawler et al. 2014), including the decline and

172 possible extirpation of hundreds of species (Powers and Jetz 2019). Assessment of the ecological

173 consequences of land-use change is critical for species management and conservation and is

174 fundamental for understanding ecological processes under contemporary environmental

175 conditions where human disturbance is a dominant feature.

176

The most fundamental ecological effects of land-use change result from conversion,

177 fragmentation and alteration of habitat (habitat modification). The pervasiveness of habitat

178 modification has led to it becoming one of the primary foci of wildlife ecology and management.

179 Because habitat modification removes or alters fundamental components of ecosystems that

180 species rely on, demographic effects are expected (e.g., reduced survival and population

181 declines; Wittmer et al. 2007, Dzialak et al. 2011b, Webb et al. 2011d). Indeed, habitat

182 modification associated with land-use has contributed to global declines in wildlife populations

183 across numerous taxa (Wilcove et al. 1998, Sala et al. 2000), and substantial losses of

184 biodiversity (Newbold et al. 2016). Studies assessing the demographic effects of habitat

185 modification provide direct inference to the processes of primary interest to conservation and

186 management. However, subtle demographic responses are difficult to detect, and these studies

187 often are costly and time consuming (i.e., responses often can only be assessed after many years

188 of study). Furthermore, if adverse effects are documented, demographic studies typically provide

189 only enough information for coarse management or conservation measures (i.e., cessation of

190 habitat modification in general) instead of more targeted measures (e.g., development-free

191 buffers around sensitive habitat [Doherty et al. 2008] or seismic exploration line width

192 specifications [Tigner et al. 2015]). 
Because assessing demographic responses to habitat modification is difficult, most studies examining effects on wildlife focus on behavior. Behavioral responses to habitat modification can be assessed over shorter time scales and often require smaller sample sizes than demographic studies to achieve sufficient statistical power to evaluate meaningful effect sizes. Behavior also provides the mechanistic link from individual to populations through effects on fitness (Berger-Tal et al. 2011, Greggor et al. 2016). Behavioral shifts in response to disturbance can include abandonment of areas important for critical life-history stages (Kuck et al. 1985, Amar et al. 2015), switching daily activity patterns (Gaynor et al. 2018), and altered space use 201 behavior (Faille et al. 2010), habitat selection (Hebblewhite and Merrill 2008), or foraging activity (Ciuti et al. 2012). Implicit in approaches focused on behavior, is the assumption that behavioral shifts affect individual fitness or populations (but see Gill et al. 2001). However, such shifts can be indicative of adaptive plasticity, which allows individuals to mitigate potential effects (Huey et al. 2003, Ghalambor et al. 2007, Tuomainen and Candolin 2011). Notably, behavior often is the primary means by which species can adjust to habitat disturbance in the 207 short term (Berger-Tal et al. 2011, Greggor et al. 2016). Thus, in the absence of data on 208 demography or fitness proxies, behavioral studies can have limited utility for understanding the implications of habitat modification on broader ecological process (Wilson et al. 2020), which often are more robust metrics for decision making in wildlife management and conservation.

Addressing behavior and demography simultaneously offers a comprehensive

212 understanding of species responses to habitat modification. Such an approach allows 213 quantification of fitness or demographic changes and identification of behavioral adjustments 214 that can help diagnose the drivers of these changes. Such work can provide powerful insight to 215 the contexts under which species can adapt to habitat modification, which is critical for effective 
management and conservation decision-making (Buchholz 2007, Caro 2007). However, whether behavioral responses to habitat modification can successfully buffer individuals from fitness effects is context-dependent. If species are displaced from limiting habitat (e.g., nesting or calving grounds), then it is likely that behavioral responses will result in reduced individual fitness and subsequent population declines. The ability to alter behavior (i.e., behavioral plasticity) can be adaptive (Ghalambor et al. 2007, 2010) but requires that environmental changes produce cues that are both recognizable and reliable (Sih et al. 2011, Sih 2013) and that habitat has not been modified in such a way to significantly reduce carrying capacity. If cues are not reliable, this can lead to the formation of ecological or evolutionary traps (Robertson et al. 2013). However, even if habitat is not limiting, or changes do not increase risk to species, behavioral responses to human disturbance can result in significant opportunity cost akin to the non-consumptive effects of predation risk (Frid and Dill 2002).

In North America, energy development has become an important driver of land-use change and habitat modification (McDonald et al. 2009). Energy development is projected to continue to alter landscapes at a continental scale for at least the next 2 decades (U.S. Energy Information Administration [EIA] 2020), and likely over a much longer period. Among the domestic energy sectors in North America, oil and natural gas (hydrocarbon) development have shown particularly rapid growth, driven largely by unconventional hydrocarbon resources (e.g., oil sands or shale natural gas; EIA 2012). These resources are widespread globally (EIA 2013), and despite recent downturns, their development is expected to continue (EIA 2020).

The habitat modification from hydrocarbon development has various effects on wildlife behavior and demography (Northrup and Wittemyer 2013). Specifically, hydrocarbon development alters a number of behaviors that are linked to fitness. The literature on wildlife 
239 responses to hydrocarbon development has documented shifts in habitat selection by mule deer

240 (Odocoileus hemionus), elk (Cervus elaphus), greater sage grouse (Centrocercus urophasianus),

241 and grizzly bears (Ursus arctos; Sawyer et al. 2006, Carpenter et al. 2010, Dzialak et al. 2011b,

242 Laberee et al. 2014, Northrup et al. 2015), altered home range patterns in mule deer and elk

243 (Webb et al. 2011a, Northrup et al. 2016b), effects on circadian patterns in entire wildlife

244 communities (Lendrum et al. 2017), and changes in song characteristics in songbirds (Francis et

245 al. 2011). Likewise, a number of studies have documented demographic responses to

246 hydrocarbon development, such as decreased survival in elk and greater sage grouse (Holloran et

247 al. 2010, Dzialak et al. 2011b, Webb et al. 2011d) and reduced recruitment, or proxies of

248 recruitment, in greater sage grouse and mule deer (Holloran et al. 2010, Johnson et al. 2016).

249 Further, hydrocarbon development increased nest predation on several songbird species

250 (Hethcoat and Chalfoun 2015) and there is some evidence that this habitat modification can lead

251 to population declines for caribou (Rangifer tarandus) and sage grouse (Sorensen et al. 2008,

252 Wasser et al. 2011, Green et al. 2017). Despite a large and growing literature documenting

253 effects, the preponderance of research focuses on behavior, with a paucity of demographic

254 analyses (Northrup and Wittemyer 2013). Understanding if behavioral responses to energy

255 development are leading to reduced fitness and subsequent declines in demographic parameters

256 is critical as natural resource managers actively work to mitigate the negative effects of

257 development (Kiesecker et al. 2009, Sochi and Kiesecker 2016).

258 In the western United States, much of the recent hydrocarbon development has been on

259 public lands that encompass habitat for ungulate populations that are the primary focus of

260 wildlife management agencies. Specifically, considerable development has occurred on the

261 winter ranges of mule deer, which historically have experienced large-scale population 
262 fluctuations across their distribution (Unsworth et al. 1999). Winter is a critical time for mule 263 deer because they can experience large die offs (White and Bartmann 1998) likely linked to 264 limited access to sufficient high-quality forage (Wallmo et al. 1977, Parker et al. 1984, Bishop et 265 al. 2009). Any substantive human activity on deer winter range is of concern to wildlife 266 managers because it could lead to decreased habitat, reductions in foraging time, reduced access 267 to forage, or increased energy expense through movement. Such effects are particularly costly on 268 winter range, which is geographically limited, where deer are nutritionally constrained (Wallmo 269 et al. 1977, Bishop et al. 2009) and snow dramatically increases the costs of locomotion (Parker 270 et al. 1984).

Hydrocarbon development involves a variety of infrastructure types that modify the

272 landscape in different ways. Well pads, facilities (including compressor stations, refining plants, 273 and personnel camps), roads, and pipelines all directly remove wildlife habitat. Accompanying 274 increases in human activity, including traffic, artificial light, and noise associated with drilling 275 can further lead to indirect habitat loss (Sawyer et al. 2009, Northrup et al. 2015). In addition, 276 development can facilitate the invasion of non-native plant species (Bergquist et al. 2007) and 277 can be accompanied by reseeding of disturbed areas, potentially leading to permanent vegetation 278 shifts or reduced plant diversity. These landscape changes are potentially concerning for mule 279 deer because the species is known to be sensitive to habitat modification and the associated 280 increases in human activity. Mule deer avoid developed areas (Nicholson et al. 1997), including 281 roads during certain times of the year (Marshal et al. 2006; Webb et al. 2011c, 2013; Lendrum et 282 al. 2012) and human activity in different forms causes mule deer to shift activity patterns and 283 move more or migrate faster (Freddy et al. 1986, Stephenson et al. 1996, Boroski and Mossman 284 1998, Lendrum et al. 2013). Deer also are displaced to varying degrees from the areas around 
285 hydrocarbon development and related infrastructure (Sawyer et al. 2006, 2017; Webb et al.

286 2011c; Northrup et al. 2015), and the associated levels of human activities at development sites

287 can largely influence displacement, with greater avoidance of sites with more people and

288 machinery (Sawyer et al. 2009, Northrup et al. 2015).

Hydrocarbon development also can influence several other ecological and behavioral

290 processes in mule deer. Home range dynamics of mule deer are affected by development, with

291 the presence of some infrastructure types eliciting reduced year-to-year overlap in ranges

292 (Northrup et al. 2016b). However, habitat heterogeneity appears to be an important predictor of

293 mule deer space use (Kie et al. 2002), and they have been shown to potentially use areas near

294 well pads and other development infrastructure because of the increased availability of forage

295 (Webb et al. 2011c), or during certain times of the year when habitat might be more limiting

296 (Marshal et al. 2006, Lendrum et al. 2012). Further, human activity can displace predators of

297 mule deer (Ripple and Beschta 2008) and energy development appears to influence the spatial

298 patterns of mule deer predation (Lendrum et al. 2018). Thus, habitat modifications from energy

299 development can have mixed effects on the species.

300 In Colorado, USA, substantial research has been conducted on mule deer responses to

301 predator reductions and habitat improvements on winter range. Collectively, this work shows

302 that the species is highly constrained by available forage (Wallmo et al. 1977) during winter. As

303 such, enhanced nutrition during winter through ad libitum feeding with pellets (Bishop et al.

304 2009) or reducing overstory trees to promote growth of palatable understory shrubs (Bergman et

305 al. 2014) has elicited positive demographic responses, including increased overwinter survival.

306 Further, predation of mule deer on winter range has been shown to be entirely compensatory in

307 Colorado (Bartmann et al. 1992, White and Bartmann 1998), and largely compensatory in other 
parts of the Intermountain West (Hurley et al. 2011), indicating populations often are at or above carrying capacity on winter range. Mule deer in Colorado also have seen a protracted decline over the last 30 years (Bergman et al. 2015). These factors raise concerns that if development causes behavioral shifts for mule deer, it could exacerbate the already difficult nutritional conditions on winter range (Bishop et al. 2009, Monteith et al. 2013), and contribute to continued population declines or slowed population growth or recovery. These concerns are amplified by recent work in Wyoming, USA, by Sawyer et al. (2017) that showed strong and consistent avoidance of the areas around natural gas development and a 36\% decline in abundance over a 15-year period. These results suggest that the strong behavioral responses of mule deer to natural gas development that have been documented elsewhere also could be associated with declines in deer populations. Thus, there is a need to improve our understanding of the demographic consequences of documented behavioral responses of deer to hydrocarbon development.

Our objective was to test hypotheses about whether and how habitat modification from hydrocarbon development influenced mule deer behavior and demography. We leveraged a unique opportunity, whereby 2 halves of a contiguous mule deer winter range area were exposed to vastly different levels of hydrocarbon development, providing a pseudo-experimental design (i.e., one area with heavy modification and one area with light modification; Fig. 1). Over a 7year period, we assessed the effect of hydrocarbon development on mule deer (hereafter deer unless otherwise indicated) behavior by examining habitat selection relative to development features and environmental factors related to cover and forage. We also examined a suite of demographic parameters measured at the individual or study area scale, including early and late winter body fat and mass, pregnancy rates, fetal counts, survival of fawns (from 6 months of age onwards), survival of adult females, lactation rates, and winter range population density. Recent 
331 studies in this broader study region have investigated different aspects of mule deer habitat

332 selection, finding a variety of behavioral responses to development (Lendrum et al. 2012, 2013;

333 Northrup et al. 2015, 2016a). Thus, we assumed that we would see differences in behavior of

334 mule deer in the 2 study areas. However, there has been no assessment of whether such

335 behavioral responses have influenced fitness or population-level demographic processes. To

336 address this gap, we tested the following alternative hypotheses and subsequent predictions:

337 Hypothesis A proposed that habitat modification elicits behavioral responses and these

338 responses lead to reductions in individual fitness and therefore reduced population size and

339 demographic rates. Under this hypothesis, we predicted that deer in the 2 study areas would

340 show different responses to cover- and forage-related covariates. Because of the large differences

341 in hydrocarbon development infrastructure between areas, we assumed differences in response to

342 development would be pervasive. Subsequently, we predicted that deer in the more heavily

343 developed area would be in worse condition and have lower survival and lower density. We did

344 not predict that we would see significant differences in pregnancy rates or fetal counts because

345 these metrics are largely invariant until deer are at or above carrying capacity.

346 Hypothesis B proposed that habitat modification elicits behavioral responses, with no

347 subsequent effect on individual fitness, population size, or demographic rates, suggesting

348 behavior effectively mitigates the demographic impacts of development. Under this hypothesis,

349 we predicted that deer in the 2 study areas would show different responses to cover- and forage-

350 related covariates, but there would be no differences in any demographic parameters at the

351 individual or study area level and density would be similar between these areas.

352 STUDY AREA 
353 The study took place between January 2008 and March 2015. The study area was the Magnolia

354 mule deer winter range in the Piceance Basin of northwestern Colorado $\left(39.954^{0} \mathrm{~N}, 108.356^{0} \mathrm{~W}\right.$;

355 Fig. 1), which encompasses an area of $184 \mathrm{~km}^{2}$. Average elevation in the area was 2,045 $\mathrm{m}$. The 356 climate was characterized by cold winters (mean Dec-Mar temp 2008-2015 in Meeker, CO= $357-3.8^{\circ} \mathrm{C}$, range $=-37.2-22.8^{\circ} \mathrm{C}$ ) and warm dry summers (mean Jun-Sep temp 2008-2015 in 358 Meeker, $\mathrm{CO}=17.5^{\circ} \mathrm{C}$, range: $-2.2-35.6^{\circ} \mathrm{C}$ ) with monsoonal precipitation in late summer. The 359 area was topographically variable with the dominant vegetation consisting of big sagebrush 360 (Artemisia tridentata) and a pinyon pine (Pinus edulis)-Utah juniper (Juniperus ostesperma) 361 shrubland complex. Other dominant shrubs included Utah serviceberry (Amalenchier utahensis), 362 mountain mahogany (Cercocarpus montanus), bitterbrush (Purshia tridentata), and mountain 363 snowberry (Symphoricarpos oreophilus). For a more detailed description of the vegetation of the 364 area see Bartmann and Steinert (1981) and Bartmann et al. (1992). Natural predators of mule 365 deer in this area included coyotes (Canis latrans), cougars (Puma concolor), bobcats (Lynx 366 rufus), and black bears (Ursus americanus; Lendrum et al. 2018). Elk and feral horses (Equus 367 ferus) also inhabited the area. This area was popular for hunting during the fall with an annual 368 average of 511 deer harvested in the wildlife management unit (Game Management Unit 22), 369 which encompassed the entire study area (Table 1). Chronic wasting disease occurred within the 370 mule deer population in this area at low levels $(2.4 \%$ prevalence in adult males in the most recent 371 assessment; $n=255,95 \% \mathrm{CI}=0.9-5.1 \%$;

372 https://cpw.state.co.us/Documents/Research/CWD/CWDprevalence_GMU-DAU_deer.pdf, 373 accessed 02 Oct. 2020). There is active cattle ranging in the area and it also contains vast 374 hydrocarbon resources that have seen active development since the 1970s. Starting in the mid375 2000s, natural gas development increased sharply but declined rapidly since 2012 (Fig. 2). 
Mule deer in this area are migratory, moving between low-elevation winter range and

377 high-elevation summer range, where they birth fawns. Deer typically occupy their winter range

378 between October and April of each year (Lendrum et al. 2014, Northrup et al. 2014b) and

379 migrate to several different summer range areas (Lendrum et al. 2014). Summer range varied in

380 elevation between 2,000 $\mathrm{m}$ and 2,800 $\mathrm{m}$ and vegetation consisted of Gambel oak (Quercus

381 gambelii), quaking aspen (Populus tremuloides), pinyon pine, Utah juniper, Douglas-fir

382 (Pseudotsuga menziesii), Engelmann spruce (Picea engelmannii), and subalpine fir (Abies

383 lasiocarpa) with mixed mountain shrublands consisting of mountain mahogany, bitterbrush, big

384 sagebrush, mountain snowberry, rubber rabbitbrush (Ericameria nauseosa), and Utah

385 serviceberry. Natural gas development density varied across summer range, with some areas

386 being free from development and other areas having $0.04-0.06$ well pads $/ \mathrm{km}^{2}$. In this area, and

387 across the Intermountain West, mule deer populations have had substantial fluctuations and large

388 declines over the last 30-50 years, with the ultimate causes remaining ambiguous (White and

389 Bartmann 1998, Unsworth et al. 1999, Bergman et al. 2015).

390 METHODS

391 Mule Deer Captures

392 Between January 2008 and March 2015, we captured mule deer using helicopter net gunning

393 (Krausman et al. 1985, Webb et al. 2008, Jacques et al. 2009, Northrup et al. 2014a; Table 2).

394 All of the below procedures were approved by the Colorado Parks and Wildlife Institutional

395 Animal Care and Use Committee (protocol numbers 17-2008 and 01-2012) and followed the 396 guidelines of the American Society of Mammalogists (Sikes 2016). Upon capture of adult female

397 deer (>1 year old; hereafter does), we administered $0.5 \mathrm{mg} / \mathrm{kg}$ of midazolam and $0.25 \mathrm{mg} / \mathrm{kg}$ of 398 Azaperone (Wildlife Pharmaceuticals, Windsor, CO, USA) and transferred them to a central 
processing site via helicopter ( $49 \%$ of captures ferried $<3.25 \mathrm{~km}, 51 \%$ ferried $3.25-6.5 \mathrm{~km}$ ). At the processing site, we weighed deer, drew blood, measured chest girth and hind foot length, and estimated their age using tooth replacement and wear (Severinghaus 1949, Robinette et al. 1957, Hamlin et al. 2000). We also obtained a body condition score by palpating the rump, and measured the thickness of subcutaneous rump fat and the depth of the longissimus dorsi muscle using ultrasound (Stephenson et al. 1998, 2002; Cook et al. 2001, 2007, 2010). We used the body condition score and ultrasound measurements to estimate the percent ingesta-free body fat of each deer (Cook et al. 2007, 2010; hereafter fat). Between December 2013 and December 2015, we determined whether each deer was lactating during December through visual examination. Lastly, we fit each deer with a global positioning system (GPS) radio-collar (G2110D Advanced Telemetry Systems, Isanti, MN, USA) set to attempt a relocation once every 5 hours and equipped with a mechanism programmed to release in 16 months after the date of capture. Collars also were equipped with a mortality beacon that was activated if the collar was immobile for $\geq 8$ hours. We attached placards to each collar with unique color and symbol combinations to allow for field-based individual identification. We monitored the deer's temperature throughout processing and released them at the processing site.

During most years, we captured the same individuals during early (Dec) and late (Mar) winter. However, there were some exceptions to this procedure during the first years of the study: 1) we did not capture any deer in March 2008, 2) we did not capture any does in December 2009, and 3) we captured new individuals in March 2010. Starting in December 2010, we captured the same individuals in early and late winter and only captured new individuals in late winter to replace any deer that died since the previous December. During late-winter captures, we assessed pregnancy using ultrasound and for does for which we did not detect a 
422 fetus, we confirmed pregnancy status using pregnancy-specific protein B from blood samples.

423 Starting in 2011, we determined the number of fetuses each deer was carrying in late-winter

424 using ultrasound (Stephenson et al. 1995). At the onset of the study, we captured deer across the

425 entire Magnolia winter range assuming they were one contiguous group. However, GPS radio-

426 collar data from the first year of the study indicated that individuals were split between the

427 northern and southern half of the winter range, with most individuals from the 2 groups

428 migrating to different summer ranges. Thus, we split our study area into north Magnolia and

429 south Magnolia (Fig. 1). We assigned deer to an area based on where they spent the majority of

430 the winter using the proportion of GPS radio-collar locations in each area (Table A1, available

431 online in Supporting Information). In addition to having different summer ranges, deer in the 2

432 areas were exposed to substantially different densities of features related to natural gas

433 development, with south Magnolia having greater road densities $\left(1.9 \mathrm{~km} / \mathrm{km}^{2}\right.$ in south Magnolia,

$4341.2 \mathrm{~km} / \mathrm{km}^{2}$ in north Magnolia), pipeline densities $\left(1.2 \mathrm{~km} / \mathrm{km}^{2}\right.$ in south Magnolia, $0.5 \mathrm{~km} / \mathrm{km}^{2}$ in

435 north Magnolia), industrial facilities ( 0.1 facilities $/ \mathrm{km}^{2}$ in south Magnolia, 0.01 facilities $/ \mathrm{km}^{2}$ in

436 north Magnolia), and well pads (0.62-0.78 pads $/ \mathrm{km}^{2}$ in south Magnolia, $0.01-0.06 \mathrm{pads} / \mathrm{km}^{2}$ in

437 north Magnolia; Figs. 1-2). Hereafter, we refer to the more heavily developed south Magnolia

438 study area as the high-development area and the north Magnolia study area as the low-

439 development area. Making valid inference to the effect of development at the study area level on

440 deer behavior and demography requires that deer are largely contained within one study area or

441 the other. To assess fidelity of the deer assigned to each study area, we conducted 2 analyses.

442 First, we estimated utilization distributions (UDs) by fitting kernel density estimators for each

443 deer and winter season (31 October through 1 May of the following year) using the ctmm

444 package in the R statistical software (Calabrese et al. 2016) assuming locations were independent 
445 and identically distributed, which equates to a conventional kernel density estimator (Calabrese 446 et al. 2016). We then calculated the proportion of the UD that overlapped with each of the

447 outlined study area boundaries in each year the animal was collared to assess if there were any

448 changes in study area use across years and to examine how often deer overlapped with a different

449 study area than the one to which it was assigned. Next, we calculated individual animal UD

450 overlap between years for each deer collared in $>1$ year to assess finer-scale fidelity of

451 individuals to their specific range area. We calculated overlap following Winner et al. (2018).

$452 \quad$ We captured mule deer fawns (deer born the previous June) using helicopter net gunning

453 December 2008-2015 (Table 3). As with does, we originally captured fawns across both study

454 areas, but then captured them separately in the low- and high-development areas beginning in

455 December 2009. We weighed and sexed fawns, fit them with a very high frequency (VHF;

456 Advanced Telemetry Systems, Isanti MN, USA) radio-collar, and released them at the capture

457 location. Fawn collars were spliced and fit with rubber surgical tubing to allow for neck growth.

458 The tubing deteriorated over time, allowing for the collar to drop off, typically on summer range.

459 As with doe collars, fawn collars were fit with placards to allow for individual identification.

460 Fawn collars were also equipped with a mortality beacon that was activated if the collar was

461 immobile for $\geq 8$ hours.

\section{Statistical Analysis of Habitat Selection}

463 We examined habitat selection using the GPS data collected from radio-collared does. To guard

464 against the potential behavioral effects of helicopter capture, we censored the first 4 days of data

465 following capture as suggested by Northrup et al. (2014a). In addition, we censored all data with

466 a dilution of precision $>10$ ( $<1 \%$ of all data; D'eon and Delparte 2005, Lewis et al. 2007).

467 Because deer are migratory in this area, and migration times vary by year and individual 
468 (Lendrum et al. 2013, Northrup et al. 2014b), we defined winter range as the time between 31

469 October and 1 May to maintain a temporally consistent sample across years. We censored any

470 data falling outside this period and any locations off of winter range during this period. We

471 examined the GPS radio-collar datasets of each individual deer and censored any apparently

472 erroneous locations (indicated by large movements induced by single outlier locations) and any

473 locations falling outside the study area boundaries (Fig. 1); we did not censor locations falling to

474 the east of the study area boundaries because this was the only boundary not delineated using

475 topographic features. The total number of censored locations equated to $<3 \%$ of all locations.

476 Lastly, we categorized each location by the winter season during which it occurred (e.g., winter

4772013 for data between Nov 2012 and Apr 2013) and whether it occurred during the night or day,

478 with night defined as the time between sunset and sunrise

479 (http://www.esrl.noaa.gov/gmd/grad/solcalc/, accessed 02 Oct. 2020).

480 We estimated resource selection functions (RSFs; Manly et al. 2002, Johnson et al. 2006)

481 for each winter and study area. Resource selection functions provide estimates of the relative

482 probability of selection of resource units based on the habitat characteristics of those resource

483 units. We estimated RSFs for day and night separately using hierarchical conditional logistic

484 regression (Duchesne et al. 2010) fit in a Bayesian framework where all parameters were

485 allowed to vary by individual, resulting in population-level parameter estimates that robustly

486 incorporated individual variability (see Northrup et al. 2015 for more details and below model

487 statement for explicit distributional assumptions). Although mule deer are typically most active

488 at dusk and dawn, our fix schedule (1 fix every 5 hours) resulted in relatively few crepuscular

489 locations. Further, other research in nearby study areas has previously shown strong contrasts in

490 behavior between night and day (Northrup et al. 2015), and our interest was in examining if there 
491 were differences between the study areas in these behaviors. Thus, we did not fit a model to data 492 during crepuscular time periods. Resource selection functions require the designation of an area 493 assumed available for selection by animals (often called the availability distribution). We 494 estimated the availability distribution using the predictor distribution (see below) from a 495 continuous-time correlated random walk model (Hooten et al. 2014). Using this approach, the 496 availability distribution is dynamic and varies for every used location, which accounts for local 497 behavior of the animal and autocorrelation in the availability distribution.

We fit continuous-time correlated random walk models for each individual and year 499 combination using the crawl package in the R statistical software (Johnson et al. 2008) and 500 following the approach of Hooten et al. (2014) to extract the predictor distribution for each 501 location. Predictor distributions are a continuously distributed prediction of where the animal is 502 expected to be at some later point in time (in our case 1 fix, or 5 hours, after a used location of 503 interest) using data from all prior movements. This distribution can be visualized as a bivariate 504 normal distribution, with the mean of the distribution being the most likely location of the 505 animal. The continuous-time correlated random walk model includes an autocorrelation term, 506 which weights movements near in time to a greater degree than previous movements and thus 507 produces estimates of availability that are dynamic in space and time. Using the mean and 508 variance of these predictor distributions, we randomly generated coordinates for the sample of 509 available locations. This approach is similar to a step-selection function (Fortin et al. 2005) but 510 provides a continuous distribution of available locations as opposed to the discrete distribution 511 that comes from using empirical turn angle and step length distributions in the originally 512 described version of this approach. Further, the traditional step selection function uses a constant 513 empirical distribution for turn angle and step length, but our approach allows for a more 
514 continuously dynamic definition of availability. Such an approach is intuitive because it serves to

515 shrink the availability distribution when the animal is stationary and expand it when they are

516 mobile. For each individual, we conducted a sensitivity analysis of the parameter estimates

517 relative to the size of the availability sample (Northrup et al. 2013). Once we determined a

518 sufficient sample size, we standardized all continuous covariates $\left(\frac{x_{i}-\bar{x}}{\operatorname{SD}(x)}\right.$, where $x_{i}$ is the $i$ th data

519 point; see below for description of covariates) and tested for pairwise correlations among

520 covariates using $|r|<0.7$ as a cutoff above which we did not include correlated covariates in the

521 same model (Dormann et al. 2013). We standardized covariates using values combined across

522 both study areas, all winter seasons, years, and day and night so that all coefficient estimates

523 would be directly comparable across models. Next, we assessed multicollinearity using condition

524 numbers, as described by Lazaridis (2007; values $>5.4$ are indicative of an ill-conditioned

525 model). This method is used prior to model fitting to assess multicollinearity. We fit the

526 hierarchical models using a Markov chain Monte Carlo (MCMC) algorithm written in the R

527 statistical language. Our model took the following form:

$$
\left[y_{t n} \mid \boldsymbol{\beta}_{n}\right]=\frac{e^{x_{y_{t n}}^{\prime} \boldsymbol{\beta}_{n}}}{\sum_{j=1}^{J} e^{\boldsymbol{x}_{\boldsymbol{j}_{t n}}^{\prime} \boldsymbol{\beta}_{n}}}
$$

$$
\boldsymbol{\beta}_{\boldsymbol{n}} \sim \operatorname{Normal}\left(\boldsymbol{\mu}_{\boldsymbol{\beta}}, \boldsymbol{\sigma}_{\boldsymbol{\beta}}^{2} \mathbf{I}\right)
$$

$$
\boldsymbol{\mu}_{\boldsymbol{\beta}} \sim \operatorname{Normal}(\mathbf{0}, 2 \mathbf{I})
$$

$$
\log \left(\sigma_{\beta_{k}}^{2}\right) \sim \operatorname{Normal}(0,1)
$$

532 where $y_{t n}$ is a resource unit represented by habitat covariates $\boldsymbol{x}_{\boldsymbol{y}_{t n}}$ that is chosen by animal $n$ at 533 time $t$ from a set of available resource units $\boldsymbol{J}$, represented by habitat covariates $\boldsymbol{x}_{\boldsymbol{j}_{\boldsymbol{t} \boldsymbol{n}}} \cdot \boldsymbol{\beta}_{\boldsymbol{n}}$ are the 534 set of coefficients related to the $k$ habitat covariates for individual $n$, and $\boldsymbol{\mu}_{\boldsymbol{\beta}}$ and $\boldsymbol{\sigma}_{\boldsymbol{\beta}}^{2}$ are the 535 population-level mean and variance of the coefficients, with I as an identity matrix. We fit this 
model to data from the night and day periods separately for each winter season-study area combination for a total of 28 models. We combined data from 2008 and 2009 because sample sizes were small at the outset of the study. Although environmental and development conditions varied between these years, the temporally specific definition of availability partially accounts for this variation. We ran the MCMC algorithm for a variable number of iterations because of

541 differences in the number needed for convergence (Table B1, available online in Supporting

542 Information), thinning chains to every twentieth iteration, and assessed convergence by

543 examining the trace plots of all parameters to ensure proper mixing. We drew inference based on 544 a combination of the coefficient magnitudes and the proportion of the posterior distributions 545 overlapping 0. Because all covariates were standardized across years and models, the magnitudes 546 are directly comparable, and thus provide inference on whether selection or avoidance of a 547 particular covariate was greater or lesser in one year or study area compared to another.

548 However, coefficient magnitude alone is not sufficient to draw robust ecological inference 549 because there can be substantial uncertainty in an effect despite a large magnitude coefficient. 550 Thus, we also made inference based on the proportion a posterior distribution that fell to either 551 side of 0 ; we considered a posterior probability of an effect $>90 \%$ to provide strong evidence of 552 an effect, between $80 \%$ and $90 \%$ moderate evidence of an effect, and <80\% weak evidence for 553 an effect.

To visualize the habitat selection patterns of deer, we mapped the mean predicted

555 population-level RSF values in each study area and year for the corresponding model (i.e., we 556 predicted habitat selection in the low-development area using the model fit to deer from the low557 development area) and binned predictions into 10 quantiles. To visualize differences in habitat 558 selection between the high- and low-development area, we then mapped the habitat selection 
559 patterns of deer in each study area to the landscape in the opposite study area; that is, for each

560 year, we mapped the mean population-level RSF values from the model fit to deer from the low-

561 development area to the landscape of the high-development area and vice versa. This exercise

562 provided a visualization of how deer in the low-development area would select habitat in a

563 heavily developed area if they showed no changes to their behavior. To quantify differences in

564 mean predicted habitat selection, we calculated the proportion of each study area that had a

565 higher RSF value, using unbinned values, for the model fit to deer from that study area compared

566 to the model fit to deer from the other study area.

567 Lastly, we assessed the area of land in each study area that was avoided by deer,

568 according to the RSF results. Because the predictions of relative probability of selection from an

569 RSF for a given year are not relative to other years, temporal comparisons of RSF values are not

570 meaningful. However, it is possible to calculate the proportion of area in each year avoided

571 relative to availability as the proportion of area where selection at the population level is less

572 than 1. Thus, for each year and study area, we calculated the proportion of land where the

573 predicted RSF value was less than 1. Further, as our results indicated a consistent avoidance of

574 drilling well pads, we calculated the proportion of the landscape within the high-development

575 area that was within $1 \mathrm{~km}$ of a drilling pad.

576 Spatial Predictor Variables of Habitat Selection

577 We chose a set of predictor variables that were related to 1) cover and forage, and 2)

578 anthropogenic features (Table 4). Cover- and forage-related variables included a terrain

579 ruggedness index (the mean difference between the elevation in a cell and that of the 8

580 neighboring cells, representing topographic cover) calculated from a United States Geological

581 Survey digital elevation model with a 30-m resolution, and daily depth of snow (representing 
582 availability of vegetation during the winter) obtained from a distributed snow evolution model

583 (Liston and Elder 2006). We validated predictions from the snow model using weather stations

584 that we deployed within the study area (Northrup et al. 2016b). Further, we assessed selection of

585 a suite of land cover-related variables. We obtained a spatial land cover layer from the Colorado

586 Vegetation Classification Project

587 (https://www.arcgis.com/home/item.html?id=893739745fcd4e05af8168b7448cda0c), which

588 classified the vegetation of our study area into 69 categories. We aggregated these categories into

5894 vegetation communities associated with security and thermal cover (represented by pinyon

590 pine, juniper, and interspersed pinyon and juniper communities), forage (represented by

591 sagebrush, sagebrush grassland mix, and mountain shrub communities), combined cover and

592 forage (represented by mixed-vegetation land cover types: sagebrush and mountain shrub

593 communities mixed with either pinyon pine, juniper, or both), and sparsely vegetated areas

594 (represented by bare ground, rock, and sparsely vegetated areas). Lastly, we calculated the

595 distance to any edges representing the transition from treed land cover to non-treed land cover as

596 a measure of distance to cover. To assess variation in conditions over time on the two study

597 areas, we qualitatively compared all of the cover and forage covariates assessed for each year

598 between the study areas. We also quantified the average normalized difference vegetation index

599 (NDVI), which is a coarse metric of plant biomass, from May through September for each year

600 and study area simply to assess study area wide variation in this parameter over years. We

601 obtained NDVI spatial layers as 7-day composites at a resolution of $1 \mathrm{~km}^{2}$ and downloaded

602 layers from the United States Geological Survey earth explorer (earthexplorer.usgs.gov, accessed

60308 Aug 2020). 
Anthropogenic covariates included the distance to the nearest road (and a quadratic term

605

606

607

608

609

610

611

612

613

614

615

616

617

618

619

620

621

622

623

624

625

626

for distance to road) obtained from a spatial layer for roads created by digitizing aerial imagery from the National Agricultural Imagery Program (NAIP); the distance to natural gas pipelines using data obtained from the White River Bureau of Land Management office and validated using the NAIP imagery; the distance to natural gas facilities (e.g., compressor stations and gas plants) obtained by digitizing NAIP imagery and validating the majority of facilities on the ground; and a suite of covariates representing the spatial density of hydrocarbon well pads. We included a quadratic effect for roads because Northrup et al. (2015) reported this form of nonlinearity in past work on mule deer in this area. In contrast, we assumed that deer would display linear avoidance or selection of pipelines and facilities relative to availability. Facilities represent a major disturbance and thus we assumed a large-scale avoidance would occur relative to availability, which in our case was drawn from a relatively small spatial extent around each point. Pipelines have relatively limited human activity associated with them and thus we did not expect a nonlinear response relative to our scale of availability. We were interested in assessing the cumulative impacts of well-pad development and thus assessed the response of deer to the number of well pads within exclusive 200-m concentric rings (hereafter buffers) to a distance of $1,000 \mathrm{~m}$ (i.e., the number of pads within $200 \mathrm{~m}$ of a deer or available location, the number of pads between $200 \mathrm{~m}$ and $400 \mathrm{~m}$, etc.). This allows for implicit assessment of cumulative effects by examining predicted responses across different numbers of well pads in different buffers (e.g., the number of pads being actively drilled within $400 \mathrm{~m}$ and the number of pads being actively drilled 400-600 m from locations).

Early in the study, when active drilling was occurring, the development landscape was highly dynamic, with the number of wells in different phases of production often varying from 
627 day to day (Fig. 2). To capture these dynamics, we obtained detailed information on the status of

628 hydrocarbon wells from the Colorado Oil and Gas Conservation Commission (COGCC;

629 cogcc.state.co.us, accessed 24 Jun 2015). The COGCC maintains a daily-updated database of the

630 status and location of every well (but not well pad) throughout Colorado. We downloaded this

631 database on 24 June 2015 and censored all wells that did not fall within $2 \mathrm{~km}$ of a mule deer GPS

632 location. Next, we grouped wells onto well pads by digitizing all well pads in the study area

633 using NAIP imagery. We grouped wells onto pads if they fell within the same digitized pad or in

634 close proximity (generally $<50 \mathrm{~m}$ ). Using these grouped data, we created a time series of well

635 pad spatial layers, accurate to the day, indicating the status of each well pad. The lifespan of a

636 well pad can be dynamic, and we expected that the different phases of this lifespan would elicit

637 different responses from deer. We categorized well pad status as abandoned, actively being

638 drilled (drilling), or producing. The most active phase is expected to be the drilling phase, which

639 is associated with large volumes of traffic, noise, artificial light, and human activity that can be

640 constant and last several weeks. The production phase, when natural gas is being actively

641 extracted, is typically associated with lower levels of human activity and can last for many years.

642 We classified well pads as drilling if there was at least 1 well that was being actively drilled. We

643 extended the drilling dates for 2 weeks before and after the start (spud) and end (test) dates to

644 account for activity associated with moving equipment onto and off of the well pad. We

645 classified well pads as producing if there were no wells being drilled and at least 1 well was

646 classified as an injection well, shut-in, or producing. Injection wells are those used for pumping

647 water or gas back underground, whereas shut-in wells are those that have been drilled but for

648 which no natural gas is being actively extracted

649 (https://cogcc.state.co.us/documents/about/COGIS_Help/glossary.htm, accessed 01 Jan. 2017). 
650 Further, we included wells in this category that were in the completion process, which entails the 651 installation of the permanent equipment used for producing natural gas. A detailed examination 652 of the status dates of the wells in this study area indicated that the time between when a well was 653 drilled and when it was completed ranged from weeks to years. The completion process is 654 expected to last only a few weeks, so we included pads in the completion phase in the producing 655 status. Although we included wells in this classification that were not actually producing natural 656 gas, the vast majority of wells in this classification were actively producing natural gas, 657 indicating the response of deer to this covariate largely represents the response to the production 658 phase. There were too few wells in the other statuses (e.g., shut-in) to separate into their own 659 classification. We classified pads as abandoned if all wells were listed as abandoned and thus, 660 presumed to not be functioning or maintained. Lastly, many wells in the study area were not 661 associated with well pads (i.e., they likely had been permitted but never constructed); thus, we 662 excluded these wells. We visited the location of many of these permitted wells and they were 663 never associated with active development. We created 10 development-related covariates from 664 these data representing the number of pads of different statuses in the concentric buffers 665 discussed above. We measured distances to the edges of pads.

We could not estimate RSF coefficients for the following covariates because of

667 insufficient development or deer locations: for the high-development area, the number of well 668 pads with active drilling within $200 \mathrm{~m}$ or between $200 \mathrm{~m}$ and $400 \mathrm{~m}$ during winter 2009 , the 669 number of well pads with active drilling within $200 \mathrm{~m}$ during winter 2010 and all drilling 670 covariates after 2010. For the low-development area, we could not estimate coefficients for any 671 drilling covariates for any years (Fig. 2). Likewise, we could not estimate coefficients for the 672 number of producing well pads within $200 \mathrm{~m}$ in the low-development area for any year. For most 
673 individuals, there were no used locations within these buffer distances. As such, a finite

674 coefficient cannot be estimated, and models fail to converge. Thus, we combined buffers to

675 achieve model convergence. For example, in the low-development area, we estimated

676 coefficients for the number of producing pads within $400 \mathrm{~m}$ and then within 200 -m concentric

677 buffers out to $1,000 \mathrm{~m}$.

\section{Field and Statistical Methods for Demographic Analyses}

679 We monitored the survival of doe and fawn mule deer using radio-telemetry daily from the 680 ground and bi-weekly from the air from a fixed-wing aircraft. Upon detection of a mortality

681 signal, we located deer on the ground and performed a necropsy to determine the cause of death.

682 During late March of each year, we conducted 3-5 mark-resight surveys in the 2 study areas via

683 helicopter to estimate deer abundance. We delineated helicopter flight paths within the 2 study

684 areas following topographic contours (e.g., drainages and ridges) using ArcMap 9.3

685 (Environmental Systems Research Institute, Redlands, CA, USA), such that the distances

686 between flight paths were approximately 500-600 m and the entirety of each study area was

687 covered. Two observers and a pilot flew the flight paths, navigating using a GPS unit, and they

688 recorded every deer that they saw as either marked with the unique identifier recorded,

689 unmarked, or marked and unidentifiable. During the mark-resight surveys, we simultaneously

690 conducted 2 telemetry surveys from a fixed-wing aircraft to determine if each marked individual

691 was within or outside of the study area boundaries. For does, we plotted the GPS locations of

692 each individual following collar recovery to evaluate whether they were within or outside of the

693 study area boundaries during surveys. Deer were seldom outside of the study area boundaries (9

694 of 181 in 2010, 2 of 163 in 2011, 8 of 191 in 2012, 9 of 208 in 2013, 10 of 220 in 2014, and 10

695 of 220 in 2015). 
We examined if there were any differences in deer body condition (early and late winter fat), age, pregnancy rates, fetal counts, lactation status, and fawn mass between study areas. Our objective was to test for an effect of development at the study area level on each metric over time. Thus, for each metric, except body fat, we fit a single linear or generalized linear model, with year and study area as categorical covariates. Further, we included an interaction between

701 year and study area. This approach allowed us to directly test for differences in each metric 702 between study areas and years in a single model as opposed to conducting multiple comparisons 703 for each year and study area combination as might be done with a $t$-test. For body fat, we fit 2 704 separate generalized linear models for beta-distributed data. The first model included the entire 705 time series of data and the second included only data from deer captured on or after December 7062013 when we began collecting information on lactation status. In the second model, we 707 included lactation status as a covariate to control for this likely important effect on individual 708 doe condition. For age, we fit a linear model to log transformed values. For pregnancy and 709 lactation status, we fit generalized linear models for Bernoulli-distributed data. For fetal counts, 710 we fit a generalized linear model for Poisson-distributed data. For fawn mass, we fit a 711 generalized linear model for gamma-distributed data. For all models we used a Type I error rate 712 of 0.05 on the coefficients to indicate statistical significance. We fit all models in the $\mathrm{R}$ statistical 713 software (R Core Team 2016).

714 We used the VHF and GPS collar monitoring data to assess survival separately for fawns 715 and does using the known-fate survival model in the statistical software program MARK (White 716 and Burnham 1999). We fit separate models because although we monitored adult females 717 continuously, fawn collars were designed to fall off before the following fall (in some years, 718 most collars fell off in late spring). Thus, we did not have matching temporal coverage of fawn 
719 and doe data, which necessitated different models. For does, we fit a set of candidate models to

720 evaluate the hypothesis that survival varied across study areas and over time. We used different

721 model structures to evaluate the temporal resolution at which survival varied (months, years, and

722 seasons). Because winter is known to be a limiting time for mule deer in Colorado, and because

723 mortality can vary by year (White et al. 1987, Bartmann et al. 1992, Bergman et al. 2014), we

724 allowed survival to vary by time (year plus season or month) in every model. Thus, in our most

725 highly parameterized (global) model, survival varied monthly between study areas, whereas in

726 the model with the fewest parameters, survival varied by season across years. We assessed 2

727 different season covariates; the first covariate allowed survival to vary among summer (June -

728 September), winter (November - April), and migration (May and October), with survival during

729 fall and spring migration being equal, and the second allowed survival to differ between fall and

730 spring migration. We compared models using Akaike's Information Criterion corrected for small

731 sample sizes $\left(\mathrm{AIC}_{c}\right.$; Burnham and Anderson 2002) and made inference based on $\mathrm{AIC}_{c}$ weights

732 and model-averaged survival estimates (Burnham and Anderson 2002). We assumed that any

733 individuals that died within 10 days of capture (does and fawns) had suffered a capture-related

734 mortality and we censored these animals from the survival analysis.

For fawns, we fit a set of candidate models to evaluate alternative hypotheses about

736 whether survival varied across time (months or winter season [Dec. - April]) and between study

737 areas. Because many fawn collars dropped off in late spring or early summer, we did not have

738 sufficient sample sizes to fit summer models; thus, we assessed fawn survival for the winter

739 season only. We compared models using $\mathrm{AIC}_{c}$ and made inference based on $\mathrm{AIC}_{c}$ weights and

740 model-averaged survival estimates (Burnham and Anderson 2002). In the most highly

741 parameterized model, survival varied monthly across years and between study areas, whereas in 
742 the simplest model survival varied by year and was constant between study areas. As with does,

743 we expected annual variation in fawn survival and thus never fit a model excluding year.

We estimated abundance for both study areas, separately, between 2009 and 2015 using

745 the immigration-emigration logit-normal mixed effects mark-resight model (McClintock et al.

746 2009, McClintock and White 2012) in MARK. This model allows for estimation of parameters

747 for the mean resighting probability across years and surveys, individual heterogeneity in

748 resighting probability within years, and differences in the population size within the survey areas

749 and the super population using the survey area (i.e., whether there was any immigration or

750 emigration). We fit models with varying combinations of these parameters in MARK and

751 assessed model parsimony using $\mathrm{AIC}_{c}$. We converted abundance estimates to density estimates

752 by dividing by the survey area (i.e., the capture area boundaries). To assess the annual rate of

753 change in population size between the 2 study areas, we refit the resulting top model to study

754 area, including a random effect for annual population size, with a mean specified as a linear trend

755 over time. We fit this model using variance components estimation, allowing for a quantification

756 of population change over time (Burnham and White 2002, Burnham 2013). Because the 2 study

757 areas had different initial abundances, the resulting estimates of realized growth were not directly

758 comparable. Thus, we converted these estimates to a proportional change over time, by dividing

759 by the intercept (i.e., abundance in year 0) and compared between study areas. We refit models,

760 as opposed to including random effects in initial models, because our primary objective was in

761 examining differences in the density estimate between study areas in each year, not growth rates.

762 The inclusion of the random effects can result in shrinkage of annual abundance estimates

763 towards the linear trend thus potentially obscuring between study area differences in some years. 
Although the outputs of models from MARK revealed if the $95 \%$ confidence intervals for

765

766

767

768

769

770

771

772

773

774

775

776

777

778

779

780

781

782

783

784

785 models of abundance (converted to density) overlapped, we were interested in assessing the

degree of confidence interval overlap between the estimates from each study area in each year.

Using the mean and standard error of the abundance estimates, we assumed a log normal

distribution and conducted a Monte Carlo simulation to assess overlap. We drew 10,000 random

samples for each study area for each year representing the suite of possible true underlying

values of abundance. We converted these to density by dividing by the area of each study area

and then calculated the overlap between the 2 resulting distributions by dividing the sum of the intersection of the distributions by the sum of their union.

\section{RESULTS}

\section{Habitat Selection}

After accounting for occasional collar malfunction, mortality, or failure to recover collars, our final GPS radio-collar dataset included 528 deer-years of data (Table 2). Fix success of GPS radio-collars averaged $>90 \%$ for the entire study. Deer displayed high fidelity to study areas (Tables A1 and A2, available online in Supporting Information). Although deer occasionally used parts of both study areas and traveled outside of both, on average there was 90\% UD overlap for deer assigned to the high-development area and 83\% UD overlap for deer assigned to the low-development area (Table A1). Further, deer assigned to the low-development area showed only $2 \%$ UD overlap with the high-development area and deer assigned to the highdevelopment area showed only 3\% UD overlap with the low-development area. Further, only 6 deer moved their winter range areas between years such that there was greater UD overlap in the opposite study area from prior years (Tables 2, A1, A2). In addition, deer displayed high fidelity 
to their specific winter ranges, with an average of $81 \%$ year-to-year UD overlap in the lowdevelopment area and 84\% year-to-year UD overlap in the high-development area (Table A2).

In the low-development area, we were unable to estimate coefficients for the response to well pads with active drilling because we rarely recorded deer within $1 \mathrm{~km}$ of such pads. In the high-development area, where drilling activity had declined to low levels after 2010 (Fig. 2), we estimated coefficients in 2008-2009 and 2010, but we combined the closest buffer distances (within either $400 \mathrm{~m}$ or $600 \mathrm{~m}$ ) in both years because of few locations within that distance. These estimates indicated that deer in the high-development area showed stronger relative avoidance of areas with more well pads that were being actively drilled in close proximity (Fig. 3; Tables C2 \& C3).

We found strong differences between the 2 study areas in the response to producing well pads (Fig. 4; Tables C1-C4). Although there was annual variation, in general, deer in the lowdevelopment area avoided the areas with more producing well pads in close proximity during both night and day, with relative avoidance increasing at closer distance buffers (Fig. 4; Tables C1 \& C2). There were not enough locations within $200 \mathrm{~m}$ of producing well pads in any year to estimate a coefficient for this buffer distance for night or day in the low-development area, indicating strong avoidance of these areas. Deer in the high-development area displayed a weaker relative avoidance of producing well pads than deer in the low-development area for most year and distance buffer combinations, with coefficient magnitudes almost always smaller than corresponding estimates for the low-development area (Fig. 4; Tables C1-C4). Further, these deer appeared to display differences in selection between night and day relative to well pads. In several years, deer avoided areas with more producing well pads in close proximity during the day, with null response or selection of areas with more pads in close proximity during 
the night (Fig. 4; Tables C3 \& C4). Deer in the low-development area showed some similar temporal patterning during some years, but this pattern was inconsistent and generally weaker than that of the high-development deer. Examining responses to well pads falling within multiple buffers simultaneously indicated a strong cumulative effect of development, with stronger avoidance of areas that had both drilling and producing well pads, or many drilling well pads falling within multiple buffer distance (Fig. 3 \& 4; Fig. 5, Tables C1-C4).

In both study areas, deer displayed differences between night and day in their response to human features other than well pads. In the low-development area, deer generally avoided areas closer to natural gas facilities during the day, but selected areas closer to these features at night, though with high uncertainty in all years and time periods (Fig. 6; Tables C1 \& C2). Also, in the low-development area, deer showed a moderate difference in responses to roads at night, with deer generally selecting areas closer to roads during the night relative to day (Fig. 7; Tables C1 \& C2). Deer displayed a relatively consistent selection of areas closer to pipelines in the lowdevelopment area, but this selection was stronger and more consistent during the night (Fig. 8;

Tables C1 \& C2). In the high-development area, deer displayed a somewhat similar temporal pattern of habitat selection relative to roads, pipelines, and facilities, though there was substantially less uncertainty in the response to facilities (Figs. 6-8; Tables C3 \& C4). Deer also displayed differences between night and day in habitat selection behavior relative to forage and cover in both areas. In the low-development area during the day, deer selected areas of less rugged terrain (Fig. 9), closer to edges (Fig. 10), and in land cover classes related to cover (Fig. 11) and showed little consistent selection or avoidance of areas in response to snow depth (Fig. 12; Tables $\mathrm{C} 1 \&$ C2). In contrast, during the night, deer did not consistently select habitat in relation to terrain ruggedness or habitat edges (Figs. 9, 10) and selected areas 
832 with deeper snow (Fig. 12) and land cover types related to forage (reference category in Fig. 11;

833 Tables C3 \& C4). Deer in both the high-development and low-development areas selected

834 habitat similarly in relation to terrain ruggedness but showed substantially different responses to

835 the other cover and forage covariates (Figs. 9-12; Tables C-C4). In the high-development area,

836 deer always selected areas closer to edges (Fig. 10) and displayed no consistent responses to

837 snow depth (Fig. 12; Tables C3 \& 4). In addition, deer in the high-development area displayed a

838 similar temporal pattern of habitat selection relative to land cover types but more strongly and

839 consistently selected cover habitat during the day than in the low-development area and did not

840 display as strong a selection for forage during the night (Fig. 11; Tables C1-C4). Cumulatively,

841 these responses resulted in strong differences in the spatial behavior of mule deer between the 2

842 study areas that also varied between night and day (Fig. 13).

843 Average measures of all covariates related to forage and cover were similar between the

844 two study areas across all years (Tables 5-6). Further, NDVI values were similar between the

845 study areas in all years (Table 7). Mapping of the RSF values showed the substantial differences

846 in habitat selection patterns between the 2 study areas (Fig. $13 \& 14$ ). When using the models fit

847 to deer from the low-development area to predict habitat selection to the high-development area,

848 in all years $>80 \%$ of the landscape had a lower RSF value than predicted when using the model

849 fit to deer from the high-development area (Fig. 14). Reflecting changes in human activity

850 throughout the study, approximately $30 \%$ of the high-development area fell within $1 \mathrm{~km}$ of well

851 pads with active drilling in $2009,22 \%$ in $2010,9 \%$ in $2011,5 \%$ in 2010 , and $0 \%$ afterwards.

852 However, our calculation of the proportion of each study area that was avoided relative to

853 availability in each year was relatively consistent for the high-development area (Table 8).

\section{Demography}


855 Across the 8 years of the study, we captured 371 unique does on multiple occasions, for a total of 856653 captures (Table 2). We also captured 766 unique fawns during this time (371 males and 395

857 females; Table 3). Despite occasional differences in mean values of age, doe body fat, pregnancy 858 metrics, and lactation status, there were no noticeable trends over time, and no consistent 859 differences between study areas (Figs. 15-17; Tables 9-10; Tables D1-D6). There were no 860 statistical differences during any winter season between the 2 study areas in early winter doe 861 body fat either when accounting for lactation status or not (Fig. 16; Table 10). Although 862 controlling for lactation status did not influence the effect of study area on body fat, deer that 863 were lactating had significantly lower body fat than those that were not $(\bar{x}$ body fat proportion of 864 lactating does $=0.09(\mathrm{SD}=0.023), \bar{x}$ body fat proportion of non-lactating does $=0.12(\mathrm{SD}=$ 865 0.034); Table 10). There were no statistical differences during any winter season between the 2 866 study areas in late winter doe fat, change in doe fat over winter, or fetal counts (Figs. 16-17; 867 Tables 9-10; Tables D1-D6). Raw lactation rates differed moderately between study areas (2013 868 low development $\bar{x}=0.45, \mathrm{SD}=0.51 ; 2013$ high development $\bar{x}=0.33, \mathrm{SD}=0.48 ; 2014$ low 869 development $\bar{x}=0.59, \mathrm{SD}=0.50 ; 2014$ high development $\bar{x}=0.46, \mathrm{SD}=0.51$ ), but 870 generalized linear models indicated that these differences were not significant (Table 9).

871 Pregnancy rates also did not appear to differ between areas (Fig. 17), though pregnancy rates 872 were $100 \%$ in some years, making it impossible to fit a model to these data assessing differences 873 in years. A generalized linear model fit to all data combined across years with only a covariate 874 for study area indicated no significant difference in pregnancy rates between the high- and low875 development areas ( $\beta$ for effect of high-development study area $=0.55, P=0.23$ ). There were 876 several significant terms for the age model, but age only differed significantly between the study 877 areas in a single year, with older does in the high-development area in 2010 (Fig. 15; Table 9). In 
878 addition, fawn mass varied significantly across years (Fig. 18), with the highest values in 879 December 2009 and significantly lighter fawns in all other years except 2013 and 2015 (Tables 880 D7-D9). However, these differences were consistent across study areas and sexes, with no 881 statistically significant differences between areas in any years and for either sex (Table 11; 882 Tables D7-D9). Males were significantly heavier than females on average (Fig. 18; Table 11). $883 \quad$ Few does died in any year of the study and there was no apparent pattern between study 884 areas (Table 2; Table E1; Figs. F1-F9). The top model for does indicated that survival varied 885 between study areas and across seasons and years, with seasons split into summer, winter, and a 886 single transition season (i.e., survival in the spring and fall transition periods were equal; Table 887 12; Fig. 19). Mean doe survival was marginally higher in the high-development area than the 888 low-development area (Fig. 19; coefficient for the effect of being in the low-development area $=$ $889-0.42 \pm 0.50[\mathrm{SE}])$. Excluding study area differences resulted in a model with nearly identical 890 weight to the top model (Table 13; Table E1). Seasonal doe survival was generally high (mean 891 monthly survival across study areas $=0.987$, range $=0.85-1.0$ ) but varied by season, with winter 892 and summer being nearly identical, and transition-season being lower (Fig. 19). Models in which 893 survival varied by month were not among the more parsimonious, with such models having zero $894 \quad \mathrm{AIC}_{c}$ weight (Table 13).

895 Raw fawn mortality counts varied substantially from year to year (Table 3). The top fawn 896 model indicated that survival varied by year only (Table 14) and had nearly twice the weight of 897 the next best model (Table 15; Table E2-E6; Figs. F10-F17). Despite the second-best model 898 suggesting evidence for study area differences, annual and monthly variation was substantially 899 stronger (Fig. 20; effect size for study area $=-0.41$, whereas average absolute value of effect size 
900 for year $=1.00)$. Further, the $95 \%$ confidence intervals for the coefficient for study area in this 901 model overlapped zero (Table E2, available online in Supporting Information).

In the low-development area, the mark-resight model with resighting probability varying 903 by individual and survey, and no immigration or emigration, was the most parsimonious among

904 the candidate models (Table 16). In the high-development area, the model with resighting

905 probability varying by survey, but not individual, and no immigration or emigration was the most 906 parsimonious (Table 16). Deer density was higher in the low-development area during each year, 907 but confidence intervals overlapped in all but 2 years (2011 and 2015; Fig. 21). Monte Carlo 908 simulations indicated that confidence interval overlap was $47 \%$ in $2010,0 \%$ in $2011,13 \%$ in $9092012,8 \%$ in $2013,21 \%$ in 2014 , and $0 \%$ in 2015, suggesting that in most years there was 910 evidence for greater density in the low-development area. The post hoc model assessing change 911 over time in abundance indicated that deer abundance increased significantly over time in both 912 study areas. Abundance increased at a greater rate in the low-development study area than the 913 high-development study area, but confidence intervals for the rate of increase overlapped (mean 914 annual increase for low- and high-development areas were 0.057 [95\% CI $=0.021-0.78]$ and $9150.045[95 \% \mathrm{CI}=0.021-0.087]$, respectively; Fig. 21).

\section{DISCUSSION}

917 We contrasted behavior and demography of mule deer between areas of heavy and light natural 918 gas development to test alternative hypotheses about how habitat modification influences the 919 species on their winter range. As expected, based on previous work in this area and others 920 (Northrup et al. 2015, Sawyer et al. 2017), we saw behavioral responses to development with 921 strong contrasts between the 2 study areas. Deer avoided infrastructure in the lightly developed 922 area where they had sufficient space to do so and selected for variables assumed to relate to 
923 forage. In the more heavily developed area, where deer did not have the space to avoid

924 infrastructure wholesale, they selected for areas with greater cover and patterned their habitat

925 selection to use areas near well pads at night. In accordance with hypothesis B, these behavioral

926 differences did not manifest as demographic effects, with no differences in any measured metric,

927 except density, between the 2 study areas. These findings indicate that deer can show remarkable

928 behavioral plasticity in relation to habitat modification, which can potentially buffer them against

929 demographic effects, at least under the development and deer densities in our study area.

930 However, deer density was lower with greater development, which suggests a demographic

931 difference between the deer in these study areas that was not captured by our design. Below we

932 discuss possible reasons for this difference.

933

The behavioral responses of deer we observed corroborate the findings of past studies on

934 the species that have shown altered habitat selection in response to hydrocarbon development

935 (Sawyer et al. 2006, 2009, 2017; Webb et al. 2011c; Northrup et al. 2015, 2016b). Further, 936 studies on other species have found similar behavioral responses to energy development and

937 related infrastructure, with elk (Webb et al. 2011b), sage grouse (Holloran et al. 2010), and

938 chestnut-collared longspurs (Calcarius ornatus; $\mathrm{Ng}$ et al. 2019) among the numerous species

939 exhibiting altered behavior. Behavioral alterations in response to habitat modification are

940 expected, as they are the initial means by which species can cope with disturbance (Berger-Tal et

941 al. 2011, Greggor et al. 2016). These alterations are typically assumed to reduce individual

942 fitness, and subsequently to affect population dynamics. Habitat selection, specifically, is a

943 behavior that is expected to influence individual fitness (Morris 1989), and variation in this

944 behavior can drive population dynamics (Matthiopoulos et al. 2015, 2019). Thus, several

945 researchers have inferred detrimental effects on species from altered habitat selection in areas 
946 disturbed by hydrocarbon development (Carpenter et al. 2010, Beckmann et al. 2012, Northrup

947 et al. 2015). Our behavioral results would, at first, seem to suggest substantial effects on

948 individual fitness through altered habitat selection in the more heavily developed area.

949 Despite the strong behavioral differences between study areas noted above, we did not 950 document a concomitant effect of natural gas development on most demographic measures,

951 supporting hypothesis B. We developed hypothesis A, whereby we predicted altered behavior 952 leading to demographic differences between the 2 areas, based on the prediction that altered 953 habitat selection would lead to reduced access to high quality forage and thus lower condition 954 and survival. However, this hypothesis was clearly refuted, with deer showing nearly identical 955 measures of all condition and demographic metrics other than density. These results stand in 956 stark contrast to the only other study that has conjointly assessed behavioral and demographic 957 effects of natural gas development on mule deer. Sawyer et al. (2017), working in a sagebrush 958 ecosystem in the Pinedale area of Wyoming before and during development, examined mule deer 959 abundance and the average distance between individuals and well pads over 15 years of ongoing 960 activity (compared to approximately 10 years of activity in our study area as of 2015). This study 961 found that mule deer were farther from natural gas development on their winter range in years 962 after development began. During this time, the population declined by $36 \%$. Mule deer in the 963 Wyoming study system appeared to avoid development more strongly than in our study area, a 964 pattern that persisted after active drilling stopped. However, the authors did not measure deer 965 body condition, reproductive parameters, or monitor fawns, making it difficult to draw 966 mechanistic links between behavioral responses and abundance. In contrast to Sawyer et al. 967 (2017), deer in our study in northwest Colorado that were subject to similarly high densities of 968 development (i.e., deer in the high-development study area) avoided well pads during the drilling 
969 phase and used all but the closest areas around well pads that were in the production phase as

970 available. Further, deer in our study appeared to increase their use of cover in the more

971 developed area. We believe that strong differences in the habitat of the 2 study systems drove

972 these contrasting findings. The Wyoming study did not conduct a formal assessment of habitat

973 selection, so it is impossible to directly compare results, but the Pinedale area consists mostly of

974 sagebrush and has limited topography, whereas our study area had substantial available tree

975 cover and complex topography. We suggest that these characteristics have allowed deer to adjust

976 behaviorally, using areas closer to well pads and other infrastructure with greater cover, whereas

977 they were displaced from large areas around development in the flatter and more open Wyoming

978 system. Our results are more similar to the response of pronghorn in the same Wyoming system

979 (Beckmann et al. 2012, 2016). Beckmann et al. (2012) examined the habitat selection patterns of 980 pronghorn in response to natural gas development over 5 years. They found that development

981 influenced pronghorn habitat selection but with no consistent direction of effect. Despite some

982 behavioral responses, Beckmann et al. (2016) found that pronghorn survival, mass, fecal

983 corticosteroids, and progesterone were nearly identical between developed and undeveloped

984 areas. However, Sawyer et al. (2019), working on pronghorn over a 15-year period in an

985 overlapping study area, documented an increase in the number of individuals abandoning their

986 ranges, which complicates interpretation of the results of Beckmann et al. (2012, 2016). These

987 congruent and contrasting findings across regions and species have implications for regulations

988 aimed at reducing impacts of hydrocarbon development on wildlife. For example, it could have

989 been potentially misleading to use the mule deer results of Sawyer et al. (2017) to assume

990 negative responses of natural gas development on pronghorn in the same area or to mule deer in

991 our study area. This suggests that, if analyses from a similar ecological context are lacking, 
992 development and mitigation plans might need to be custom fit to the species and area of interest

993 to ensure effectiveness.

994 Mule Deer Behavior and Natural Gas Development

995 Deer in our 2 study areas displayed markedly different patterns of habitat selection. We interpret 996 these results as the manifestation of different behavioral tactics from a species that is known to

997 be highly philopatric (Robinette 1966, Garrott et al. 1987, Northrup et al. 2016b), and from 998 individuals who displayed remarkable fidelity. In the low-development area, deer could simply 999 move to areas of their home ranges far from development while likely maintaining their typical 1000 habitat selection patterns. Such a tactic was possible because of the low density of development, 1001 and thus relatively larger amount of undeveloped habitat within their ranges to which they could 1002 be displaced. Deer in the high-development area did not have undeveloped areas within their 1003 winter ranges to which they could move and thus modified their behavior at a finer scale, 1004 focusing on access to cover over access to forage. Similar patterns of reduced direct interaction 1005 with development without large-scale abandonment of ranges has been seen in previous studies 1006 of elk and mule deer in areas with active natural gas development (Webb et al. 2011a,b). 1007 However, other studies offer contrasting findings, with pronghorn and mule deer in Wyoming 1008 displaying potential abandonment or large-scale avoidance of developed winter range areas 1009 (Sawyer et al. 2017, 2019) and sage grouse showing reduced lek attendance near well pads 1010 (Walker et al. 2007). All of these species typically display philopatry, so these findings suggest 1011 that abandonment occurs where alternative habitats, within an animals range, offering cover from 1012 the disturbance are not available.

Although the above differences in habitat selection of deer might seem nuanced, they 1014 represent strong contrasts in spatial behavior between the 2 areas, which can have important 
1015 implications for conservation planning (Harju et al. 2011). The mapping of habitat selection

1016 patterns of deer from the low-development area to the landscape in the high-development area

1017 indicated compromised behavior assuming consistent habitat selection patterns (Fig. 14).

1018 However, deer in the high-development area regularly used habitat that naïve deer would avoid.

1019 Our condition measures did not support a link between these behavioral shifts and physiological

1020 costs, possibly because of the generally low forage quality on mule deer winter range (Wallmo et

1021 al. 1977). Notably, all deer were in a net negative energy balance on their winter range,

1022 regardless of density of development or forage availability in the area. This contradictory finding

1023 is likely because the major decline in condition that deer experience over the winter supersedes

1024 benefits that use of areas with more forage may provide during this period (Monteith et al. 2013).

1025 If low forage quality is the reason for the lack of any documented demographic response,

1026 then it is possible that greater attention should be paid to management and mitigation options

1027 during the late winter and early spring when green-up begins. This period likely is particularly

1028 important for deer to begin to recoup condition losses over the winter, and behavioral responses

1029 to development likely are more impactful. Furthermore, given the importance of the summer

1030 range for critical stages of reproduction and net energy balance gains that carry deer through

1031 winter, summer disturbance could be more important than previously considered. Indeed, the

1032 timing of development relative to important life-history stages is likely critical to understanding

1033 how different species might respond to development during different times of the year. As

1034 mentioned above, our results are similar to those found for pronghorn on their winter range in

1035 Wyoming, whereby no physiological costs were associated with altered habitat selection around

1036 energy development infrastructure. Beckmann et al. (2016) posited that because pronghorn

1037 already experience substantial condition declines over winter, any effect of habitat loss from 
energy development was masked. These results contrast with those from avian studies that have examined the effect of energy development during the breeding season. $\mathrm{Ng}$ et al. (2019) documented reduced parental care in chestnut-collared longspurs closer to development infrastructure, leading to fewer offspring fledged in these areas. Likewise, Walker et al. (2007) documented declines in male sage grouse attendance at leks when they were located closer to energy development. However, even for avian species during the critical nesting period, these results are not always consistent; Ludlow and Davis (2018) found a range of effects (both positive and negative) of hydrocarbon wells on waterfowl and shorebird nest site selection but no effect on daily nest survival. Considering these contrasting findings, close attention should be paid to the timing of development activities relative to life-history stages. Indeed, for mule deer, behavioral responses during the fawning period could have greater demographic consequences than what we show in this study and thus further research into this potential is warranted.

\section{Mule Deer Demography and Natural Gas Development}

Our demographic results indicate that at the current development and deer population densities, natural gas well pads in the production phase on winter range are not affecting the measured individual demographic and physiological parameters in our study area. Our sample sizes were large and thus we had the power to detect relatively small differences between study areas and years. For example, the probability of detecting a difference in fawn survival between 0.95 and 0.85 ( 0.95 was approximately the average monthly survival for the less developed area) was

\subsection{Estimated differences in survival were usually smaller than 0.1 , and deer in the high-} development area had marginally higher survival than in the low-development area in general. For does, differences between study areas were always small (the mean of the absolute value of differences in monthly survival between areas was 0.015 ) and would require annual sample sizes 
1061 approaching 1,000 collared does to see statistically significant differences if survival truly varied 1062 by that small amount. Thus, the lack of differences in demographic parameters (particularly 1063 survival) is a robust finding.

1064 The demographic parameters we measured were indicative of a population below 1065 carrying capacity. In particular, survival of fawns in this study was high (average of overwinter 1066 model-averaged survival estimates for the low-development area $=0.77$ and for the high1067 development area =0.78; Fig. 20). Forrester and Wittmer (2013) reviewed survival rates of mule 1068 deer throughout their range, and the survival estimates for fawns from our study exceed nearly 1069 every study reviewed. Further, these survival rates were higher than comparable studies 1070 conducted in this study area or in similar habitat that experimentally removed predators 1071 (Bartmann et al. 1992, Hurley et al. 2011), assessed habitat improvements (Bergman et al. 2014), 1072 or reduced deer density (White and Bartmann 1998). During certain years, fawn survival in our 1073 study was similar to those reported by Bishop et al. (2009) who fed deer pellets ad libitum during 1074 winter to intentionally raise the carrying capacity in their study system, though on average their 1075 estimates were higher than ours. Doe survival was on par with estimates from other studies 1076 (mean model-averaged annual survival estimate for low-development area $=0.82$ and for the 1077 high-development area $=0.85$ ). For large ungulates, adult survival is the most sensitive vital rate 1078 but typically varies little, with population dynamics often driven by recruitment (Gaillard et al. 1079 1998). Thus, the comparatively high fawn survival in our study further strengthens our 1080 impression that these populations were below carrying capacity. Other demographic and 1081 physiological parameters that we measured were similar or exceeded those in other studies. 1082 Specifically, early and late winter doe body fat was the same or higher in our study than in 1083 similar studies (Bishop et al. 2009; Monteith et al. 2013, 2014; Bergman et al. 2018). Only does 
1084 receiving supplemental feed ad libitum in Bishop et al. (2009) had higher body fat than those in 1085 our study. Pregnancy rates in our study also were on par or higher than those in other studies 1086 (Bishop et al. 2009, Freeman et al. 2014, Monteith et al. 2014), and fawn mass was comparable 1087 to Hurley et al. (2011) and substantially higher than during the 1980s in the same ecosystem as 1088 our study (Bartmann et al. 1992). These comparisons indicate that in both study areas, deer were 1089 not strongly limited by habitat availability as might be expected under substantial habitat 1090 modification.

Mule deer in the Piceance Basin declined substantially in the 1990s (White and Bartmann 1092 1998, Unsworth et al. 1999). Although this past work did not overlap spatially with our current 1093 study, they took place in the same ecosystem. During those studies, winter range deer densities 1094 were 5-6 times higher than in our study (White and Bartmann 1998). Thus, the current 1095 demographic rates likely represent a rebounding population that is below carrying capacity, 1096 where winter range habitat is not strongly limiting. Under these conditions, our results indicate 1097 that the current density of development in the producing phase is not actively affecting these 1098 populations, despite the strong behavioral differences between the 2 study areas. However, 1099 habitat modification from natural gas development could induce negative demographic 1100 consequences that occurred prior to our work (potentially accounting for the differences in 1101 densities observed; see discussion below) or could not be detected in our study. First, because 1102 deer appear to be well below carrying capacity, we are unable to determine if habitat 1103 modification has permanently altered the density of deer that this landscape is able to support. 1104 Thus, if deer densities continue to increase, we may observe differences in demographic 1105 responses manifest as a function of different carrying capacities or observe density-dependent 1106 effects sooner on the more heavily developed area. Likewise, most of the winters during our 
study were mild (i.e., little snow and relatively mild temperatures, with snow melting in early spring), except for the first and fourth winters. Mule deer populations have traditionally been

1109 limited by winter range forage availability (Wallmo et al. 1977, Parker et al. 1984, Bishop et al.

1110 2009) and thus we would expect some interaction between the high level of habitat modification

1111 and winter severity, whereby deer in the high-development area might have particularly

1112 depressed demographic rates during harsh winters. Because winters were relatively mild during

1113 our study, we were unable to test this interaction. Long-term declines in winter severity

1114 associated with climate change may further reduce the chances of such a scenario.

1115 Critically, our study began after natural gas development had peaked. In fact, intensive

1116 drilling and associated activity levels declined through the duration of the study, thereby relaxing

1117 displacement of deer most strongly associated with the drilling phase of development. Sawyer et

1118 al. $(2006,2017)$ examined deer responses to natural gas development in a before-during study

1119 design and found large-scale displacement of deer after initiation, associated with reductions in

1120 abundance. Thus, we are uncertain if there were similar responses in our population, which

1121 might account for observed differences in density, and if the remaining deer that were studied are

1122 those less prone to negative effects from development (e.g., habituated to development). Strong

1123 demographic effects in response to the initial habitat modification before our study would

1124 explain the documented differences in deer density, but we lack the information required to make

1125 this inference. In addition, although this study primarily assessed the response of deer to well

1126 pads in the later stages of development (i.e., production), the responses to drilling were strong

1127 and the area affected by this activity was large, particularly in the first year of the study. Drilling

1128 appears to have shifted deer activity to other areas of their home ranges as evidenced by the high

1129 fidelity to winter use areas and the relatively consistent proportion of the high-development area 
1130 where deer selection was reduced. The subsequent reduction of drilling activity then increased

1131 the relative selection of areas where wells were previously being drilled. If drilling activity

1132 increases above previous levels in coming years, we are uncertain of how this will affect deer

1133 behavior and demography, particularly now that deer density is higher than during the more

1134 active drilling phase. At very high densities of drilling activity, deer could display habituation

1135 similar to responses to production activity, or alternatively, the avoidance that we documented

1136 could produce demographic effects. Further, because drilling activity is associated with

1137 substantial noise, it might also affect the ability of deer to avoid predators if they did habituate to

1138 drilling activity at higher densities. There is likely some level above which deer or pad densities

1139 are high enough to affect demography and population dynamics, but conditions during our study

1140 were apparently below this threshold. Identifying these thresholds will be complicated because it

1141 is likely a function of the species, habitat, weather, climate, and timing of development. For

1142 example, Sawyer et al. (2017) found larger-scale avoidance by naïve (i.e., not previously

1143 exposed) mule deer and Sawyer et al. (2019) found substantial increases in the number of naïve

1144 pronghorn completely abandoning their study areas. Although our study did not include naïve

1145 deer, comparisons to our results suggest deer can persist at higher densities in proximity to

1146 development in our study area with more vegetative and topographic cover. Likewise, life-

1147 history stage is important when considering thresholds; Sawyer et al. (2020), working with mule

1148 deer during migration, found deer use during migration strongly declined at surface disturbance

1149 levels of around 3\%. However, they did not assess any demographic consequences of these

1150 responses. In our heavily developed study area, around 4\% of the landscape is disturbed by well

1151 pads, facilities, and roads. Deer still use these areas, albeit in an altered manner, but we

1152 documented no large-scale avoidance as in the study by Sawyer et al. (2020). 
1154 discussed above, despite nearly identical demographic and physiological measures between the 2

1155 study areas, there was, potentially, a lower rate of population growth in the high-development

1156 area and consistently higher point estimates of density in the low-development area (though

1157 confidence intervals overlapped for linear trends in density and for annual density estimates in

1158 most years). Four possible processes could cause differences in density, although we do not

1159 currently have the data to directly address which of these is most likely. First, habitat quality

1160 could be different between the 2 areas and thus carrying capacity could be lower in the more

1161 heavily developed area. However, remotely sensed covariates linked to habitat quality (e.g.,

1162 NDVI, snow cover) were similar between the 2 study areas. Further if habitat quality was

1163 different, we would expect to see differences in overwinter change in body fat. As such, we

1164 assume this is unlikely. Second, it is possible fawns in the high-development area lost more mass

1165 during the winter than those in the low-development area, but these differences did not manifest

1166 themselves over winter. Given summer is the time when deer gain energy (Monteith et al. 2013),

1167 this seems unlikely. Recapture of individual fawns in late winter would be needed to address this 1168 hypothesis.

1169 The third possible explanation is that the onset of development reduced deer density in 1170 the more heavily developed area. This reduction could have occurred from deer abandoning their 1171 winter ranges, or from a reduction in carrying capacity due to larger-scale avoidance of well pads 1172 during the construction and drilling phases. Either process could have led to lower density 1173 compared to the low-development area. Given deer are highly philopatric even in the presence of 1174 substantial development (Robinette 1966, Garrott et al. 1987, Northrup et al. 2016b), and our 1175 fidelity analysis exemplified this behavior in over 400 individuals in this study, we do not find 
1176 evidence that deer are currently abandoning their winter ranges to a greater degree in the high-

1177 development area. Sawyer et al. (2006) and Sawyer et al. (2019) found deer and pronghorn,

1178 respectively, to be strongly displaced at the onset of development. Thus, density differences

1179 could result from displacement of sensitive individuals before initiation of our study, or the

1180 emigration of juveniles, which we did not follow for multiple years. If density was reduced in the

1181 high-development area at the onset of development, regardless of the mechanism, then the

1182 apparent population growth that we documented would be a result of low density relative to

1183 carrying capacity.

The last explanation for potential differences in population trends and density in the 2

1185 study areas is that neonatal or fetal survival could be different between the 2 areas because of

1186 differences in predator abundance or habitat quality on summer range, which would lead to

1187 lower overall recruitment rates despite similar overwinter fawn survival. Lower recruitment rates

1188 would explain differences in population growth rates despite all other demographic parameters

1189 being nearly identical. Because neonatal fawn mortality tends to be high in mule deer generally

1190 (Pojar and Bowden 2004, Lomas and Bender 2007), as confirmed in this study area (Peterson

1191 2016, Peterson et al. 2017), any differences in survival of this age class could be an important

1192 driver of population dynamics. Further, if there were differences in habitat quality between the

1193 summer ranges, then lower recruitment in one area could lead to the documented consistency in

1194 other demographic parameters. That is, if recruitment is low in the high-development area, it

1195 could lead to similar overwinter fawn survival and similar condition metrics between the 2 areas,

1196 despite differences in available habitat because of the subsequent reductions in density.

1197 However, our data do not support this possibility because doe body fat in both March (prior to

1198 departure for summer range) and December (after arrival back on winter range) were consistent 
between study areas across all years. The similar body fat values indicate that, on average, deer were recovering similar fat stores on both summer ranges. Similarly, for the few years that we

1201 collected lactation status information, we saw no differences between the study areas in body fat 1202 after controlling for lactation, suggesting differences in recruitment (which affect female body 1203 condition) were not a factor. Deer that are still lactating in December likely still have fawns at 1204 heel, and thus the similar fat values for lactating deer in both study areas suggests minimal 1205 differences in habitat quality between the summer ranges. This finding would suggest that 1206 recruitment rates are either not different between the study areas or only the fattest does in the 1207 high-development study area were rearing fawns (an unlikely condition given deer reproductive 1208 strategies). It is also possible that recruitment differed, but these differences were too small to 1209 affect study area-level differences in body fat. Such small differences in survival from birth to 6 1210 months of age probably could affect differences in population growth, and thus cannot be 1211 discounted as a driver of potential differences in density. A congruent study being conducted in 1212 this area on deer reproduction found some potential evidence for lower birth rates (i.e., more 1213 stillbirths) on the summer range of the high-development area, compared to the summer range of 1214 the low-development area (Peterson 2016, Peterson et al. 2017). However, differences were not 1215 consistent across time and additional study areas were sampled to provide sufficient power, thus 1216 providing weak evidence that neonatal survival or birth rates were influencing patterns of density 1217 in our current study. The only other measure of recruitment we had was lactation rates in 1218 December, which did indicate potential, but non-significant, differences in recruitment on the 2 1219 study areas.

1220 In light of the above discussion, our inability to estimate recruitment is a clear limitation 1221 of this study. We had only 2 years of data on lactation rates, which, based on the negative 
1222 relationship with doe body condition that we documented, is likely to represent some index of

1223 recruitment. More detailed information on recruitment rates would greatly clarify our results.

1224 Specifically, study area-level estimates would allow us to better resolve the differences in

1225 population dynamics. Currently, our results only show that density and, to a lesser extent,

1226 population growth appeared higher in the low-development area, but the mechanism is unclear.

1227 For example, all of the following are reasonable explanations for lower density on the more

1228 developed area: lower recruitment, lower initial density, abandonment of ranges upon initiation

1229 of development, reduced carrying capacity due to habitat loss from development, or innate

1230 differences in habitat quality.

1231 Understanding the degree to which development affects further population growth will

1232 require continued examination under higher densities of well pads and deer, assessments of

1233 responses on summer range, and monitoring fawns through the entirety of their first year of life.

1234 We focused on winter range because deer in these areas inhabit summer ranges that are far apart

1235 and differ strongly in development activity and forage quality (Lendrum et al. 2012, 2013, 2014;

1236 Northrup et al. 2014b). Furthermore, mule deer management in Colorado and the rest of the

1237 Intermountain West has traditionally focused on winter range because deer face limited access to

1238 forage (Wallmo et al. 1977, Parker et al. 1984, Bishop et al. 2009) and can experience

1239 pronounced mortality during this period (White and Bartmann 1998). Thus, winter range

1240 assessments have the strongest implications for current management practices. In light of our

1241 findings, and reduced winter severity from climate change, increased attention should be focused

1242 on deer on their summer range.

1243 The Use of Habitat Selection Analyses to Assess Effects of Human Disturbance 
1244 Habitat selection has long been used to assess wildlife responses to human activity and

1245 foundational ecological theory provides a pathway for inference to population and demographic

1246 responses through individual fitness (Fretwell and Lucas 1969, Charnov 1976, Frid and Dill

1247 2002). Further, recent work has directly quantified links between habitat selection and population

1248 dynamics (Matthiopoulos et al. 2019). The numerous challenges involved in obtaining detailed

1249 demographic information (i.e., large numbers of marked individuals needed for long time

1250 periods) result in many studies requiring inferential leaps between behavioral responses,

1251 individual fitness, and population consequences. Our results highlight the need for caution when

1252 inferring population consequences from habitat selection analyses (see also Wilson et al. 2020),

1253 and indicate that some behavioral responses may be indicative of adaptive phenotypic plasticity

1254 (Ghalambor et al. 2007, Tuomainen and Candolin 2011) and not result in negative population-

1255 level consequences. This is particularly true for species that are adaptable to disturbance and

1256 where the disturbance is relatively short lived (i.e., less than the lifespan of an individual).

1257 Our study focused on habitat selection of a relatively adaptable species on winter range

1258 where forage resources are typically limiting (Bishop et al. 2009). Thus, as mentioned above, it

1259 might be that nutrition is so limiting during this time that any behavioral response to

1260 development does not further restrict access to forage given the little nutritional value during

1261 winter. Further, the manner in which animals respond to disturbance is likely impossible to intuit

1262 from demographic data alone. Combining behavioral and demographic studies, as we have done

1263 here, provides a mechanistic understanding of how animals respond to human disturbance, which

1264 is subsequently crucial for developing effective mitigation measures (Dzialak et al. 2011a). For

1265 example, in our study, deer used areas closer to development by shifting use of these areas to the

1266 night time and increasing their use of cover habitat. This finding provides strong support for 
1267 mitigation measures aimed at maintaining such cover habitat (discussed below) and reducing the

1268 human footprint during the drilling phase. Although pairing detailed demographic and behavioral

1269 studies will continue to be difficult, because of the need for sustained long-term funding and

1270 diverse expertise, pressing management issues warrant such work to obtain a more complete

1271 understanding of human-modified systems and potential mitigation measures.

1272 Limitations

1273 Despite the large sample sizes of individuals in our study, we had a few key limitations that

1274 could be improved upon in future research. Although a concurrent study measured neonatal fawn

1275 (i.e., birth through 6 months of age) survival (Peterson 2016, Peterson et al. 2017), this study did

1276 not directly match our design either spatially or temporally, thus limiting our ability to infer

1277 effects on population dynamics from their results; concurrent information on neonatal survival

1278 across our entire study period would have been valuable to help clarify differences in density

1279 between our 2 study areas. However, this type of data is costly and difficult to collect,

1280 particularly in our study area where fawning areas on summer range were often $>100 \mathrm{~km}$ apart

1281 and dispersed. Likewise, the results of our study highlight the potential need to more closely

1282 monitor the condition of fawns throughout the entire first year of life. Although we saw no

1283 differences in early winter fawn mass, fawns in the more heavily developed study area possibly

1284 lost more mass over winter, leading to potentially lower survival during migration and over the

1285 summer. If we had collected this information, we might have been better able to assess the

1286 differences in density between the 2 study areas. Again, collecting these data would be costly,

1287 requiring recapture of $>100$ fawns or improved technology allowing annual survival estimates.

1288 Perhaps most critically, a clear limitation of our study was that we began research after the

1289 initiation of natural gas development. Sawyer et al. (2017) documented a strong response by 
mule deer to the initiation of natural gas development, providing a strong argument for procuring

1291 data before, during, and after development activity when possible. In addition to these

1292 limitations, that deer in our study migrated to different summer ranges adds complexity to the

1293 inference. Although we were able to account for potential differences in nutrition along

1294 migratory routes and over summer by measuring early winter fawn mass and doe condition (all

1295 of which were statistically indistinguishable between the 2 study areas), a better study design

1296 would include deer with shared summer ranges.

1297 In addition to the above limitations, our combined behavioral and demographic analyses

1298 could be improved upon in future work. An ideal design would quantitatively integrate the

1299 behavioral and demographic data. For example, RSF coefficients might be used as covariates in

1300 survival models to directly assess whether behavior influenced survival, or the effect of metrics

1301 such as body fat on habitat selection behavior might be examined. In our study, we were limited

1302 by a few factors that made such an analysis impractical or uninformative. First, our RSF analyses

1303 included a large number of parameters, making direct integration complex. That is, to include

1304 RSF coefficients as covariates in a survival model would require $>15$ parameters in some years.

1305 Likewise, we were unable to estimate some coefficients in some years (e.g., for drilling well

1306 pads), again complicating analyses. Further, survival of does was so high that our models could

1307 not support a large number of covariates. Recent advances in habitat selection modeling provide

1308 a roadmap for designing future studies that can better integrate demography and RSFs

1309 (Matthiopoulos et al. 2015, 2019), but our design did not allow for following these examples.

1310 Lastly, aside from density, there were no documented differences in demographic metrics

1311 between the 2 study areas. Thus, had we been able to better integrate these datasets, it is unclear 1312 what inference such analyses would have provided. 


\section{MANAGEMENT IMPLICATIONS}

1314 Our findings support focusing mitigation efforts on reducing impacts during the construction and

1315 drilling phases of hydrocarbon development and limiting human activity and noise during the

1316 longer production phase. Such measures should include strategic spatial configuration of

1317 infrastructure that reduces road networks or minimizes construction of new roads, encourages

1318 multi-well pads and directional drilling (where possible) to reduce the footprint, noise (and

1319 artificial light) reducing retaining walls, and remote liquid-gathering systems (Sawyer et al.

1320 2009). Most of the wells in our study area are directionally drilled from pads with multiple wells,

1321 which substantially reduced development density and resulted in a spatial configuration that

1322 allowed deer to respond behaviorally.

1323 Our results in combination with those of other studies on mule deer (Sawyer et al. 2017,

1324 2020) support maintaining cover habitat and refuge areas free from development so that deer can

1325 adapt their behavior without being displaced wholesale from their ranges. Landscape planning to

1326 ensure the minimization of the industrial footprint (e.g., roads, pipeline, processing stations) is

1327 critical for the maintenance of such cover habitat. More dispersed development, provided it does

1328 not lead to a significantly larger road network, might be more effective at minimizing impacts to

1329 deer and is supported by the surface disturbance thresholds documented by Sawyer et al. (2020).

1330 Although focusing mitigation on the drilling phase of development seems intuitive, our results

1331 offer some optimism that natural gas impacts might be more short-lived than previously thought

1332 and provides for feasible options for mule deer conservation in development planning

1333 considerations.

1334 Our modeling framework also provides results that can be used to infer development

1335 density thresholds and the subsequent behavioral responses. By focusing on the number of 
1336 development features within different buffers, we were able to assess the cumulative impact of

1337 development on deer behavior (e.g., Fig. 5). This information could be used by developers and

1338 land and wildlife managers in conjunction to identify potential development scenarios that

1339 minimize the behavioral effects of development on deer. For example, spacing infrastructure

1340 such that areas with multiple well pads in buffers that were avoided by deer should be limited.

1341 However, under similar ecological contexts as in our system (i.e., rugged terrain and ample

1342 vegetative cover) and similar deer and development densities, these behavioral responses are

1343 unlikely to elicit demographic effects. As such, we suggest that the development densities during

1344 our study could be used as a starting point for further work assessing the potential existence of

1345 thresholds of development above which demographic effects might occur, and future

1346 development planning could maintain similar thresholds to minimize population-level impacts in

1347 areas with similar habitat characteristics (i.e., $\leq 0.8 \mathrm{pads} / \mathrm{km}^{2}$ on pinyon-juniper-dominated

1348 winter range in generally rugged terrain). In areas similar to our study area in land cover and

1349 topography, the RSF models for the high-development study area could be used to assess how

1350 deer would be anticipated to respond under different scenarios. Maps that show predictions from

1351 the high-development RSF model to the low-development area (Fig. 14) indicate how deer might

1352 respond behaviorally if the low-development area saw increased industrial activity. Such maps

1353 could be augmented with proposed development plans to further assess behavioral responses of

1354 deer and identify a strategy to extract natural gas with the least behavioral effect on deer.

1355 However, deer do not exist in these landscapes in isolation, and development strategies that are

1356 beneficial for them might affect more sensitive species, such as greater sage grouse. Thus,

1357 multiple species will need to be considered in development plans. 
1359 on winter ranges. Our results do not provide strong evidence for or against these restrictions

1360 because of the limited amount of drilling during our study (i.e., initiated as drilling declined on

1361 the landscape). It might be tempting to interpret the lack of demographic response to the

1362 production phase as evidence for removing drilling restrictions and speeding the transition to

1363 production, but this could be misguided. If the density differences recorded in this study were a

1364 function of an initial response by deer to drilling, removing restrictions could elicit local

1365 population declines through larger-scale avoidance as seen in mule deer and pronghorn in

1366 Wyoming (Sawyer et al. 2019, 2020). Thus, we propose that planning be based on conditions

1367 present on proposed development areas until further research focused on scenarios with more

1368 active drilling over longer periods of time can be conducted. Ultimately, the variability evident in

1369 our results when compared to stronger responses of deer and pronghorn from other systems,

1370 suggests development planners should acknowledge the dynamics involved in wildlife-energy

1371 development interactions. Considerations of topographic and vegetative diversity and whether or

1372 not there is evidence that animals are habitat limited should be incorporated into development

1373 planning options. This approach may ultimately foster a collaborative and likely more successful

1374 planning process.

1375 It remains to be seen whether the development in our area will limit mule deer

1376 populations at higher densities. The direct habitat conversion caused by roads, well pads, and

1377 facilities will at some threshold have demographic consequence for these populations. Thus,

1378 concerned managers should focus late-stage mitigation on recontouring and revegetating well

1379 pads, and reducing the overall road network and reclaiming roads or restricting public access

1380 thereon. 


\section{ACKNOWLEDGMENTS}

1382 We thank K. Wilson, L. Wolfe, D. Collins, M. Fisher, C. Bishop, E. Bergman, D. Finley, D.

1383 Freddy, and numerous field technicians for project coordination and field assistance; P. Lukacs

1384 and G. White assisted with the initial study design. We thank Quicksilver Air, Inc. for deer

1385 captures, and L. Gepfert and Coulter Aviation, Inc. for fixed-wing aircraft support. We thank J.

1386 Tigner, and S. Downing for assistance with interpretation of development data, T. Hobbs and M.

1387 Hooten for statistical advice and G. E. Liston with assistance in modeling snow depth. H.

1388 Johnson and R. Conrey provided helpful comments on an earlier draft of the manuscript prior to 1389 submission. We thank H. Sawyer, S. Webb, and 5 anonymous reviewers for comments that 1390 greatly improved the manuscript. Funding and support for mule deer captures and monitoring 1391 were provided by Colorado Parks and Wildlife (CPW), White River Field Office of Bureau of 1392 Land Management, ExxonMobil Production/XTO Energy, WPX Energy, Shell Exploration and 1393 Production, EnCana Corp., Marathon Oil Corp., Federal Aid in Wildlife Restoration (W-185-R), 1394 the Colorado Mule Deer Foundation, the Colorado Mule Deer Association, Safari Club 1395 International, Colorado Oil and Gas Conservation Commission, and the Colorado State 1396 Severance Tax. This research used the Colorado State University Information Science 1397 Technology Center Cray High Performance Computing system supported by National Science 1398 Foundation Grant CNS-0923386.

\section{LITERATURE CITED}

1400 Amar, A., R. E. Simmons, and S. C. Krüger. 2015. Anthropogenic activities influence the 1401 abandonment of bearded vulture (Gypaetus barbatus) territories in southern Africa. Condor: Ornithological Applications 117:94-107. 
Bartmann, R. M., and S. F. Steinert. 1981. Distribution and movements of mule deer in the White River Drainage, Colorado. Colorado Division of Wildlife, Fort Collins, USA.

Bartmann, R. M., G. C. White, and L. H. Carpenter. 1992. Compensatory mortality in a Colorado mule deer population. Wildlife Monographs 121:1-39.

Beckmann, J. P., K. Murray, R. G. Seidler, and J. Berger. 2012. Human-mediated shifts in animal habitat use: sequential changes in pronghorn use of a natural gas field in Greater Yellowstone. Biological Conservation 147:222-233.

Beckmann, J. P., S. H. Olson, R. G. Seidler, and J. Berger. 2016. Sub-lethal effects of energy development on a migratory mammal - the enigma of the North American pronghorn. Global Ecology and Conservation 6:36-47.

Berger-Tal, O., T. Polak, A. Oron, Y. Lubin, B. P. Kotler, and D. Saltz. 2011. Integrating animal behavior and conservation biology: a conceptual framework. Behavioral Ecology 22:236-239.

Bergman, E. J., C. R. Anderson, Jr., C. J. Bishop, A. A. Holland, and J. M. Northrup. 2018. Variation in ungulate body fat: individual versus temporal effects. Journal of Wildlife Management 82:130-137.

Bergman, E. J., C. J. Bishop, D. J. Freddy, G. C. White, and P. F. Doherty, Jr. 2014. Habitat management influences overwinter survival of mule deer fawns in Colorado. Journal of Wildlife Management 78:448-455.

Bergman, E. J., P. F. Doherty, G. C. White, and A. A. Holland. 2015. Density dependence in mule deer: a review of evidence. Wildlife Biology 21:18-29. 
1424 Bergquist, E., P. Evangelista, T. Stohlgren, and N. Alley. 2007. Invasive species and coal bed

1425

1426

1427

1428

1429

1430

1431

1432

1433

1434

1435

1436

1437

1438

1439

1440

1441

1442

1443

1444

1445

methane development in the Powder River Basin, Wyoming. Environmental Monitoring and Assessment 128:381-394.

Bishop, C. J., G. C. White, D. J. Freddy, B. E. Watkins, and T. R. Stephenson. 2009. Effect of enhanced nutrition on mule deer population rate of change. Wildlife Monographs 172:128.

Boroski, B. B., and A. S. Mossman. 1998. Water use patterns of mule deer (Odocoileus hemionus) and the effects of human disturbance. Journal of Arid Environments 38:561569.

Buchholz, R. 2007. Behavioural biology: an effective and relevant conservation tool. Trends in Ecology \& Evolution 22:401-407.

Burnham, K. P. 2013. Variance components and random effects models in MARK. Program MARK: a gentle introduction. http://www. phidot. org/software/mark/docs/book/. Accessed 15 March, 2015.

Burnham, K. P., and D. R. Anderson. 2002. Model selection and multimodel inference: a practical information-theoretic approach. Springer Science \& Business Media, New York, New York, USA.

Burnham, K. P., and G. C. White. 2002. Evaluation of some random effects methodology applicable to bird ringing data. Journal of Applied Statistics 29:245-264.

Calabrese, J. M., C. H. Fleming, and E. Gurarie. 2016. ctmm: an R package for analyzing animal relocation data as a continuous-time stochastic process. Methods in Ecology and Evolution 7:1124-1132. 
Sikes. R. S. 2016. 2016 Guidelines of the American Society of Mammalogists for the use of wild mammals in research and education. Journal of Mammalogy 97:663-688.

Caro, T. 2007. Behavior and conservation: a bridge too far? Trends in Ecology \& Evolution 22:394-400.

Carpenter, J., C. Aldridge, and M. S. Boyce. 2010. Sage-grouse habitat selection during winter in Alberta. Journal of Wildlife Management 74:1806-1814.

1452 Charnov, E. L. 1976. Optimal foraging, the marginal value theorem. Theoretical Population

Ciuti, S., J. M. Northrup, T. B. Muhly, S. Simi, M. Musiani, J. A. Pitt, and M. S. Boyce. 2012. Effects of humans on behaviour of wildlife exceed those of natural predators in a landscape of fear. PloS One 7:e50611.

Cook, R. C., J. G. Cook, D. L. Murray, P. Zager, B. K. Johnson, and M. W. Gratson. 2001. Development of predictive models of nutritional condition for Rocky Mountain elk. Journal of Wildlife Management 65:973-987.

Cook, R. C., J. G. Cook, T. R. Stephenson, W. L. Myers, S. M. Mccorquodale, D. J. Vales, L. L. Irwin, P. B. Hall, R. D. Spencer, S. L. Murphie, K. A. Schoenecker, and P. J. Miller. 2010. Revisions of rump fat and body scoring indices for deer, elk, and moose. Journal of Wildlife Management 74:880-896.

Cook, R. C., T. R. Stephenson, W. L. Myers, J. G. Cook, and L. A. Shipley. 2007. Validating predictive models of nutritional condition for mule deer. Journal of Wildlife Management 71:1934-1943. 
1467 D'eon, R. G., and D. Delparte. 2005. Effects of radio-collar position and orientation on GPS

1468

1469

1470

1471

1472

1473

1474

1475

1476

1477

1478

1479

1480

1481

1482

1483

1484

1485

1486

1487

1488 radio-collar performance, and the implications of PDOP in data screening. Journal of Applied Ecology 42:383-388.

Doherty, K. E., D. E. Naugle, B. L. Walker, and J. M. Graham. 2008. Greater sage-grouse winter habitat selection and energy development. Journal of Wildlife Management 72:187-195.

Dormann, C. F., J. Elith, S. Bacher, C. Buchmann, G. Carl, G. Carré, J. R. G. Marquéz, B. Gruber, B. Lafourcade, P. J. Leitão, et al. 2013. Collinearity: a review of methods to deal with it and a simulation study evaluating their performance. Ecography 36:27-46.

Duchesne, T., D. Fortin, and N. Courbin. 2010. Mixed conditional logistic regression for habitat selection studies. Journal of Animal Ecology 79:548-555.

Dzialak, M. R., S. M. Harju, R. G. Osborn, J. J. Wondzell, L. D. Hayden-Wing, J. B. Winstead, and S. L. Webb. 2011a. Prioritizing conservation of ungulate calving resources in multiple-use landscapes. PloS One 6:14597.

Dzialak, M. R., S. L. Webb, S. M. Harju, J. B. Winstead, J. J. Wondzell, J. P. Mudd, and L. D. Hayden-Wing. 2011b. The spatial pattern of demographic performance as a component of sustainable landscape management and planning. Landscape Ecology 26:775-790.

Faille, G., C. Dussault, J.-P. Ouellet, D. Fortin, R. Courtois, M.-H. St-Laurent, and C. Dussault. 2010. Range fidelity: the missing link between caribou decline and habitat alteration? Biological Conservation 143:2840-2850.

Foley, J. A., R. DeFries, G. P. Asner, C. Barford, G. Bonan, S. R. Carpenter, F. S. Chapin, M. T. Coe, G. C. Daily, H. K. Gibbs, et al. 2005. Global consequences of land use. Science 309:570-574. 
Forrester, T. D., and H. U. Wittmer. 2013. A review of the population dynamics of mule deer and black-tailed deer Odocoileus hemionus in North America. Mammal Review 43:292_308.

Fortin, D., H. L. Beyer, M. S. Boyce, D. W. Smith, T. Duchesne, and J. S. Mao. 2005. Wolves influence elk movements: behavior shapes a trophic cascade in Yellowstone National Park. Ecology 86:1320-1330.

Francis, C. D., C. P. Ortega, and A. Cruz. 2011. Different behavioural responses to anthropogenic noise by two closely related passerine birds. Biology Letters 7:850-852.

Freddy, D. J., W. M. Bronaugh, and M. C. Fowler. 1986. Responses of mule deer to disturbance by persons afoot and snowmobiles. Wildlife Society Bulletin 14:63-68.

Freeman, E. D., R. T. Larsen, M. E. Peterson, C. R. Anderson, Jr., K. R. Hersey, and B. R. McMillan. 2014. Effects of male-biased harvest on mule deer: implications for rates of pregnancy, synchrony, and timing of parturition. Wildlife Society Bulletin 38:806-811.

Fretwell, S. D., and H. L. Lucas. 1969. On territorial behavior and other factors influencing habitat distribution in birds. Acta Biotheoretica 19:16-36.

Frid, A., and L. M. Dill. 2002. Human-caused disturbance stimuli as a form of predation risk. Ecology and Society 6:11.

Gaillard, J.-M., M. Festa-Bianchet, and N. G. Yoccoz. 1998. Population dynamics of large herbivores: variable recruitment with constant adult survival. Trends in Ecology \& Evolution 13:58-63.

Garrott, R. A., G. C. White, R. M. Bartmann, L. H. Carpenter, and A. W. Alldredge. 1987. Movements of female mule deer in northwest Colorado. Journal of Wildlife Management 51:634-643. 
1512 Gaynor, K. M., C. E. Hojnowski, N. H. Carter, and J. S. Brashares. 2018. The influence of 1513 human disturbance on wildlife nocturnality. Science 360:1232-1235.

1514 Ghalambor, C. K., L. M. Angeloni, and S. P. Carroll. 2010. Behavior as phenotypic plasticity.

1515 Pages 90-107 in D. F. Westneat and C. W. Fox, editors. Evolutionary Behavioral Ecology 1516 Oxford University Pres, New York, USA.

1517 Ghalambor, C. K., J. K. McKay, S. P. Carroll, and D. N. Reznick. 2007. Adaptive versus non1518 adaptive phenotypic plasticity and the potential for contemporary adaptation in new 1519 environments. Functional Ecology 21:394-407.

1520 Gibson, L., A. J. Lynam, C. J. A. Bradshaw, F. He, D. P. Bickford, D. S. Woodruff, S. 1521 Bumrungsri, and W. F. Laurance. 2013. Near-complete extinction of native small mammal fauna 25 years after forest fragmentation. Science 341:1508-1510.

1523 1524 1525 1526 1527 1528 1529 1530 1531 1532 1533 1534

Gill, J. A., K. Norris, and W. J. Sutherland. 2001. Why behavioural responses may not reflect the population consequences of human disturbance. Biological Conservation 97:265-268.

Green, A. W., C. L. Aldridge, and M. S. O'Donnell. 2017. Investigating impacts of oil and gas development on greater sage-grouse. Journal of Wildlife Management 81:46-57.

Greggor, A. L., O. Berger-Tal, D. T. Blumstein, L. Angeloni, C. Bessa-Gomes, B. F. Blackwell, C. C. St Clair, K. Crooks, S. De Silva, and E. Fernández-Juricic. 2016. Research priorities from animal behaviour for maximising conservation progress. Trends in Ecology \& Evolution 31:953-964.

Haberl, H., K. H. Erb, F. Krausmann, V. Gaube, A. Bondeau, C. Plutzar, S. Gingrich, W. Lucht, and M. Fischer-Kowalski. 2007. Quantifying and mapping the human appropriation of net primary production in earth's terrestrial ecosystems. Proceedings of the National Academy of Sciences 104:12942-12947. 
Hamlin, K. L., D. F. Pac, C. A. Sime, R. M. DeSimone, and G. L. Dusek. 2000. Evaluating the accuracy of ages obtained by two methods for Montana ungulates. Journal of Wildlife Management 64:441-449.

Hansen, M. J., and A. P. Clevenger. 2005. The influence of disturbance and habitat on the presence of non-native plant species along transport corridors. Biological Conservation 125:249-259.

Harju, S., M. Dzialak, R. Osborn, L. Hayden-Wing, and J. Winstead. 2011. Conservation planning using resource selection models: altered selection in the presence of human activity changes spatial prediction of resource use. Animal Conservation 14:502-511.

Harris, G., S. Thirgood, J. G. C. Hopcraft, J. Cromsigt, and J. Berger. 2009. Global decline in aggregated migrations of large terrestrial mammals. Endangered Species Research 7:5576.

Hebblewhite, M., and E. Merrill. 2008. Modelling wildlife-human relationships for social species with mixed-effects resource selection models. Journal of Applied Ecology $45: 834-844$.

Hethcoat, M. G., and A. D. Chalfoun. 2015. Towards a mechanistic understanding of humaninduced rapid environmental change: a case study linking energy development, nest predation and predators. Journal of Applied Ecology 52:1492-1499.

Holloran, M. J., R. C. Kaiser, and W. A. Hubert. 2010. Yearling greater sage-grouse response to energy development in Wyoming. Journal of Wildlife Management 74:65-72.

Hooten, M. B., E. M. Hanks, D. S. Johnson, and M. W. Alldredge. 2014. Temporal variation and scale in movement-based resource selection functions. Statistical Methodology 17:82-98. 
1557 Huey, R. B., P. E. Hertz, and B. Sinervo. 2003. Behavioral drive versus behavioral inertia in evolution: a null model approach. American Naturalist 161:357-366.

Hurley, M. A., J. W. Unsworth, P. Zager, M. Hebblewhite, E. O. Garton, D. M. Montgomery, J.

1560

1561

1562

1563

1564

1565

1566

1567

1568

1569

1570

1571

1572

1573

1574

1575

1576

1577

R. Skalski, and C. L. Maycock. 2011. Demographic response of mule deer to experimental reduction of coyotes and mountain lions in southeastern Idaho. Wildlife Monographs 178:1-33.

Jacques, C. N., J. A. Jenks, C. S. Deperno, J. D. Sievers, T. W. Grovenburg, T. J. Brinkman, C. C. Swanson, and B. A. Stillings. 2009. Evaluating ungulate mortality associated with helicopter net-gun captures in the northern Great Plains. Journal of Wildlife Management $73: 1282-1291$.

Johnson, C. J., S. E. Nielsen, E. H. Merrill, T. L. McDonald, and M. S. Boyce. 2006. Resource selection functions based on use-availability data: theoretical motivation and evaluation methods. Journal of Wildlife Management 70:347-357.

Johnson, D. S., J. M. London, M. A. Lea, and J. W. Durban. 2008. Continuous-time correlated random walk model for animal telemetry data. Ecology 89:1208-1215.

Johnson, H. E., J. R. Sushinsky, A. Holland, E. J. Bergman, T. Balzer, J. Garner, and S. E. Reed. 2016. Increases in residential and energy development are associated with reductions in recruitment for a large ungulate. Global Change Biology 23:578-591.

Kie, J. G., R. T. Bowyer, M. C. Nicholson, B. B. Boroski, and E. R. Loft. 2002. Landscape heterogeneity at differing scales: effects on spatial distribution of mule deer. Ecology 83:530-544. 
1578 Kiesecker, J. M., H. Copeland, A. Pocewicz, and B. McKenney. 2009. Development by design:

1579 blending landscape-level planning with the mitigation hierarchy. Frontiers in Ecology

$1580 \quad$ and the Environment 8:261-266.

1581 Krausman, P. R., J. J. Hervert, and L. L. Ordway. 1985. Capturing deer and mountain sheep with 1582 a net-gun. Wildlife Society Bulletin 13:71-73.

1583 Kuck, L., G. L. Hompland, and E. H. Merrill. 1985. Elk calf response to simulated mine 1584 disturbance in Southeast Idaho. Journal of Wildlife Management 49:751-757.

1585 Laberee, K., T. A. Nelson, B. P. Stewart, T. McKay, and G. B. Stenhouse. 2014. Oil and gas 1586 infrastructure and the spatial pattern of grizzly bear habitat selection in Alberta, Canada. 1587 Canadian Geographer 58:79-94.

1588 Lawler, J. J., D. J. Lewis, E. Nelson, A. J. Plantinga, S. Polasky, J. C. Withey, D. P. Helmers, S. 1589 Martinuzzi, D. Pennington, and V. C. Radeloff. 2014. Projected land-use change impacts 1590 on ecosystem services in the United States. Proceedings of the National Academy of $1591 \quad$ Sciences 111:7492-7497.

1592 Lazaridis, A. 2007. A note regarding the condition number: the case of spurious and latent 1593 multicollinearity. Quality \& Quantity 41:123-135.

1594 Lendrum, P. E., C. R. Anderson, Jr., R. A. Long, J. G. Kie, and R. T. Bowyer. 2012. Habitat 1595 selection by mule deer during migration: effects of landscape structure and natural-gas 1596 development. Ecosphere 3:art82.

1597 Lendrum, P. E., C. R. Anderson, Jr., K. L. Monteith, J. A. Jenks, and R. T. Bowyer. 2013. 1598 Migrating mule deer: effects of anthropogenically altered landscapes. PloS One $1599 \quad 8: e 64548$. 
Lendrum, P. E., C. R. Anderson, Jr., K. L. Monteith, J. A. Jenks, and R. T. Bowyer. 2014. Relating the movement of a rapidly migrating ungulate to spatiotemporal patterns of forage quality. Mammalian Biology 79:369-375.

Lendrum, P. E., K. R. Crooks, and G. Wittemyer. 2017. Changes in circadian activity patterns of a wildlife community post high-intensity energy development. Journal of Mammalogy $98: 1265-1271$.

Lendrum, P. E., J. M. Northrup, C. R. Anderson, G. E. Liston, C. L. Aldridge, K. R. Crooks, and G. Wittemyer. 2018. Predation risk across a dynamic landscape: effects of anthropogenic land use, natural landscape features, and prey distribution. Landscape Ecology 33:157170.

Lewis, J. S., J. L. Rachlow, E. O. Garton, and L. A. Vierling. 2007. Effects of habitat on GPS collar performance: using data screening to reduce location error. Journal of Applied Ecology 44:663-671.

Li, X., G. Chen, X. Liu, X. Liang, S. Wang, Y. Chen, F. Pei, and X. Xu. 2017. A new global land-use and land-cover change product at a 1-km resolution for 2010 to 2100 based on human-environment interactions. Annals of the American Association of Geographers 107:1040-1059.

Liston, G. E., and K. Elder. 2006. A distributed snow-evolution modeling system (SnowModel). Journal of Hydrometeorology 7:1259-1276.

Lomas, L. A., and L. C. Bender. 2007. Survival and cause-specific mortality of neonatal mule deer fawns, north-central New Mexico. Journal of Wildlife Management 71:884-894. 
1621 Ludlow, S. M., and S. K. Davis. 2018. Oil and natural gas development influence nest-site

1622

1623

1624

1625

1626

1627

1628

1629

1630

1631

1632

1633

1634

1635

1636

1637

1638

1639

1640

1641

1642 selection and nest survival of upland-nesting waterfowl and shorebirds. Wildlife Society Bulletin 42:57-66.

Manly, B. F. J., L. L. McDonald, D. L. Thomas, T. L. Mcdonald, and W. P. Erickson. 2002. Resource selection by animals: statistical design and analysis for field studies. Second edition. Kluwer Academic Publishers, Dordrecht, The Netherlands.

Marshal, J. P., V. C. Bleich, P. R. Krausman, M. L. Reed, and N. G. Andrew. 2006. Factors affecting habitat use and distribution of desert mule deer in an arid environment. Wildlife Society Bulletin 34:609-619.

Matthiopoulos, J., J. Fieberg, G. Aarts, H. L. Beyer, J. M. Morales, and D. T. Haydon. 2015. Establishing the link between habitat selection and animal population dynamics. Ecological Monographs 85:413-436.

Matthiopoulos, J., C. Field, and R. MacLeod. 2019. Predicting population change from models based on habitat availability and utilization. Proceedings of the Royal Society B: Biological Sciences 286:20182911.

McClintock, B. T., and G. C. White. 2012. From NOREMARK to MARK: software for estimating demographic parameters using mark-resight methodology. Journal of Ornithology 152:641-650.

McClintock, B. T., G. C. White, K. P. Burnham, and M. A. Pryde. 2009. A generalized mixed effects model of abundance for mark-resight data when sampling is without replacement. Pages 271-289 in D. L. Thomson, E. G. Cooch, and M. J. Conroy, editors. Modeling demographic processes in marked populations. Springer, New York, New York, USA. 
1643

1644

1645

1646

1647

1648

1649

1650

1651

1652

1653

1654

1655

1656

1657

1658

1659

1660

1661

1662

1663

McDonald, R. I., J. Fargione, J. Kiesecker, W. M. Miller, and J. Powell. 2009. Energy sprawl or energy efficiency: climate policy impacts on natural habitat for the United States of America. PloS One 4:e6802.

Monteith, K. L., V. C. Bleich, T. R. Stephenson, B. M. Pierce, M. M. Conner, J. G. Kie, and R. T. Bowyer. 2014. Life-history characteristics of mule deer: effects of nutrition in a variable environment. Wildlife Monographs 186:1-62.

Monteith, K. L., T. R. Stephenson, V. C. Bleich, M. M. Conner, B. M. Pierce, and R. T. Bowyer. 2013. Risk-sensitive allocation in seasonal dynamics of fat and protein reserves in a longlived mammal. Journal of Animal Ecology 82:377-388.

Morris, D. W. 1989. Density-dependent habitat selection: testing the theory with fitness data. Evolutionary Ecology 3:80-94.

Newbold, T., L. N. Hudson, A. P. Arnell, S. Contu, A. De Palma, S. Ferrier, S. L. L. Hill, A. J. Hoskins, I. Lysenko, H. R. P. Phillips, et al. 2016. Has land use pushed terrestrial biodiversity beyond the planetary boundary? A global assessment. Science 353:288-291.

Ng, C. S., P. G. Des Brisay, and N. Koper. 2019. Chestnut-collared longspurs reduce parental care in the presence of conventional oil and gas development and roads. Animal Behaviour 148:71-80.

Nicholson, M. C., R. T. Bowyer, and J. G. Kie. 1997. Habitat selection and survival of mule deer: tradeoffs associated with migration. Journal of Mammalogy 78:483-504.

Northrup, J. M., C. R. Anderson, Jr., M. B. Hooten, and G. Wittemyer. 2016a. Movement reveals scale dependence in habitat selection of a large ungulate. Ecological Applications 26:8. 
Northrup, J. M., C. R. Anderson, Jr., and G. Wittemyer. 2014a. Effects of helicopter capture and handling on movement behavior of mule deer. Journal of Wildlife Management 78:731738.

Northrup, J. M., C. R. Anderson, Jr., and G. Wittemyer. 2015. Quantifying spatial habitat loss from hydrocarbon development through assessing habitat selection patterns of mule deer. Global Change Biology 21:3961-3970.

Northrup, J. M., C. R. Anderson, Jr., and G. Wittemyer. 2016b. Environmental dynamics and anthropogenic development alter philopatry and space-use in a North American cervid. Diversity and Distributions 22:547-557.

Northrup, J. M., M. B. Hooten, C. R. Anderson, Jr., and G. Wittemyer. 2013. Practical guidance on characterizing availability in resource selection functions under a use-availability design. Ecology 94:1456-1463.

Northrup, J. M., A. B. A. Shafer, C. R. Anderson, Jr., D. W. Coltman, and G. Wittemyer. $2014 b$. Fine-scale genetic correlates to condition and migration in a wild cervid. Evolutionary Applications 7:937-948.

Northrup, J. M., and G. Wittemyer. 2013. Characterising the impacts of emerging energy development on wildlife, with an eye towards mitigation. Ecology Letters 16:112-125.

Parker, K. L., C. T. Robbins, and T. A. Hanley. 1984. Energy expenditures for locomotion by mule deer and elk. Journal of Wildlife Management 48:474-488.

Peterson, M. E. 2016. Reproductive success, habitat selection, and neonatal mule deer mortality in a natural gas development area. Dissertation, Colorado State University, Fort Collins, USA. 
Peterson, M. E., C. R. Anderson, Jr., J. M. Northrup, and P. F. Doherty, Jr. 2017. Reproductive success of mule deer in a natural gas development area. Wildlife Biology 2017:wlb.00341.

Pojar, T. M., and D. C. Bowden. 2004. Neonatal mule deer fawn survival in west-central Colorado. Journal of Wildlife Management 68:550-560.

Powers, R. P., and W. Jetz. 2019. Global habitat loss and extinction risk of terrestrial vertebrates under future land-use-change scenarios. Nature Climate Change 9:323-329.

R Core Team. 2016. R: a language and environment for statistical computing. R Foundation for Statistical Computing, Vienna, Austria.

Ripple, W. J., and R. L. Beschta. 2008. Trophic cascades involving cougar, mule deer, and black oaks in Yosemite National Park. Biological Conservation 141:1249-1256.

Robertson, B. A., J. S. Rehage, and A. Sih. 2013. Ecological novelty and the emergence of evolutionary traps. Trends in Ecology \& Evolution 28:552-560.

Robinette, W. 1966. Mule deer home range and dispersal in Utah. Journal of Wildlife Management 30:335-349.

Robinette, W. L., D. A. Jones, G. Rogers, and J. S. Gashwiler. 1957. Notes on tooth development and wear for Rocky Mountain mule deer. Journal of Wildlife Management 21:134-153.

Sala, O. E., F. Stuart Chapin, III, J. J. Armesto, E. Berlow, J. Bloomfield, R. Dirzo, E. HuberSanwald, L. F. Huenneke, R. B. Jackson, A. Kinzig, et al. 2000. Global biodiversity scenarios for the year 2100. Science 287:1770-1774.

Sawyer, H., J. P. Beckmann, R. G. Seidler, and J. Berger. 2019. Long-term effects of energy development on winter distribution and residency of pronghorn in the Greater Yellowstone Ecosystem. Conservation Science and Practice 1:e83. 
1709 Sawyer, H., M. J. Kauffman, and R. M. Nielson. 2009. Influence of well pad activity on winter

1710

1711

1712

1713

1714

1715

1716

1717

1718

1719

1720

1721

1722

1723

1724

1725

1726

1727

1728

1729 habitat selection patterns of mule deer. Journal of Wildlife Management 73:1052-1061.

Sawyer, H., N. M. Korfanta, R. M. Nielson, K. L. Monteith, and D. Strickland. 2017. Mule deer and energy development-long-term trends of habituation and abundance. Global Change Biology 23:4521-4529.

Sawyer, H., M. S. Lambert, and J. A. Merkle. 2020. Migratory disturbance thresholds with mule deer and energy development. Journal of Wildlife Management 84:930-937.

Sawyer, H., R. M. Nielson, F. Lindzey, and L. L. McDonald. 2006. Winter habitat selection of mule deer before and during development of a natural gas field. Journal of Wildlife Management 70:396-403.

Severinghaus, C. W. 1949. Tooth development and wear as criteria of age in white-tailed deer. Journal of Wildlife Management 13:195-216.

Sih, A. 2013. Understanding variation in behavioural responses to human-induced rapid environmental change: a conceptual overview. Animal Behaviour 85:1077-1088.

Sih, A., M. C. Ferrari, and D. J. Harris. 2011. Evolution and behavioural responses to humaninduced rapid environmental change. Evolutionary Applications 4:367-387.

Sochi, K., and J. Kiesecker. 2016. Optimizing regulatory requirements to aid in the implementation of compensatory mitigation. Journal of Applied Ecology 53:317-322.

Sorensen, T., P. D. McLoughlin, D. Hervieux, E. Dzus, J. Nolan, B. O. B. Wynes, and S. Boutin. 2008. Determining sustainable levels of cumulative effects for boreal caribou. Journal of Wildlife Management 72:900-905. 
1730 Stephenson, T. R., V. C. Bleich, B. M. Pierce, and G. P. Mulcahy. 2002. Validation of mule deer

1731

1732

1733

1734

1735

1736

1737

1738

1739

1740

1741

1742

1743

1744

1745

1746

1747

1748

1749

1750

1751

1752 body composition using in vivo and post-mortem indices of nutritional condition. Wildlife Society Bulletin 30:557-564.

Stephenson, T. R., K. J. Hundertmark, C. C. Schwartz, and V. Van Ballenberghe. 1998. Predicting body fat and body mass in moose with ultrasonography. Canadian Journal of Zoology 76:717-722.

Stephenson, T. R., M. R. Vaughan, and D. E. Andersen. 1996. Mule deer movements in response to military activity in southeast Colorado. Journal of Wildlife Management 60:777-787.

Stephenson, T. R., J. Ward Testa, G. P. Adams, R. Garth Sasser, C. Schwartz, and K. Hundertmark. 1995. Diagnosis of pregnancy and twinning in moose by ultrasonography and serum assay. Alces 31:167-172.

Tigner, J., E. M. Bayne, and S. Boutin. 2015. American marten respond to seismic lines in northern Canada at two spatial scales. PloS One 10:e0118720.

Tuomainen, U., and U. Candolin. 2011. Behavioural responses to human-induced environmental change. Biological Reviews 86:640-657.

Unsworth, J. W., D. F. Pac, G. C. White, and R. M. Bartmann. 1999. Mule deer survival in Colorado, Idaho, and Montana. Journal of Wildlife Management 63:315-326.

U.S. Energy Information Administration [EIA]. 2012. Annual energy review 2011. EIA, Washington, D.C., USA.

U.S. Energy Information Administration [EIA]. 2013. Shale oil and gas resoruces are globally abundant. EIA, Washington, D.C., USA.

U.S. Energy Information Administration [EIA]. 2020. Annual energy outlook 2020. EIA, Washington, D.C., USA. 
1753 Vitousek, P. M., H. A. Mooney, J. Lubchenco, and J. M. Melillo. 1997. Human domination of $1754 \quad$ Earth's ecosystems. Science 277:494-499.

1755 Walker, B. L., D. E. Naugle, and K. E. Doherty. 2007. Greater sage-grouse population response 1756 to energy development and habitat loss. Journal of Wildlife Management 71:2644-2654.

1757 Wallmo, O. C., L. H. Carpenter, W. L. Regelin, R. B. Gill, and D. L. Baker. 1977. Evaluation of 1758 1759 deer habitat on a nutritional basis. Journal of Range Management 30:122-127.

Wasser, S. K., J. L. Keim, M. L. Taper, and S. R. Lele. 2011. The influences of wolf predation,

Webb, S. L., M. R. Dzialak, S. M. Harju, L. D. Hayden-Wing, and J. B. Winstead. $2011 a$. Influence of land development on home range use dynamics of female elk. Wildlife Research 38:163-167.

Webb, S. L., M. R. Dzialak, S. M. Harju, L. D. Hayden-Wing, and J. B. Winstead. $2011 b$. Effects of human activity on space use and movement patterns of female elk. Wildlife Society Bulletin 35:261-269.

Webb, S. L., M. R. Dzialak, K. L. Kosciuch, and J. B. Winstead. 2013. Winter resource selection by mule deer on the Wyoming-Colorado border prior to wind energy development.

$1770 \quad$ Rangeland Ecology and Management 66:419-427.

1771 Webb, S. L., M. R. Dzialak, R. G. Osborn, S. M. Harju, J. Wondzell, L. Hayden-Wing, and J. B. 1772 Winstead. 2011c. Using pellet groups to assess response of elk and deer to roads and 1773 energy development. Wildlife Biology in Practice 7:32-40. 
1774 Webb, S. L., M. R. Dzialak, J. J. Wondzell, S. M. Harju, L. D. Hayden-Wing, and J. B.

1775

1776

1777

1778

1779

1780

1781

1782

1783

1784

1785

1786

1787

1788

1789

1790

1791

1792

1793

1794

Winstead. 2011d. Survival and cause-specific mortality of female Rocky Mountain elk exposed to human activity. Population Ecology 53:483-493.

Webb, S. L., J. S. Lewis, D. G. Hewitt, M. W. Hellickson, and F. C. Bryant. 2008. Assessing the helicopter and net gun as a capture technique for white-tailed deer. Journal of Wildlife Management 72:310-314.

White, G. C., and R. M. Bartmann. 1998. Effect of density reduction on overwinter survival of free-ranging mule deer fawns. Journal of Wildlife Management 62:214-225.

White, G. C., and K. P. Burnham. 1999. Program MARK: survival estimation from populations of marked animals. Bird Study 46:S120-S139.

White, G. C., R. A. Garrott, R. M. Bartmann, L. H. Carpenter, and A. W. Alldredge. 1987. Survival of mule deer in northwest Colorado. Journal of Wildlife Management 51:852859.

Wilcove, D. S., D. Rothstein, J. Dubow, A. Phillips, and E. Losos. 1998. Quantifying threats to imperiled species in the United States. BioScience 48:607-615.

Wilson, M. W., A. D. Ridlon, K. M. Gaynor, S. D. Gaines, A. C. Stier, and B. S. Halpern. 2020. Ecological impacts of human-induced animal behaviour change. Ecology Letters 23:in press.

Winner, K., M. J. Noonan, C. H. Fleming, K. A. Olson, T. Mueller, D. Sheldon, and J. M. Calabrese. 2018. Statistical inference for home range overlap. Methods in Ecology and Evolution 9:1679-1691. 
1795 Wittmer, H. U., B. N. McLellan, R. Serrouya, and C. D. Apps. 2007. Changes in landscape

1796 composition influence the decline of a threatened woodland caribou population. Journal 1797 of Animal Ecology 76:568-579.

1798 
Figure 1. Location of study area for assessment of effects of natural gas development on mule deer, 2008-2015, including study-area outlines, roads, natural gas well pads, and facilities in the north and south Magnolia winter range study areas in the Piceance Basin, Colorado, USA. North Magnolia is the northern polygon with low development and south Magnolia is the southern polygon with high development. Black arrows in the top right panel show the general migration directions of deer in the 2 study areas.

Figure 2. Number of natural gas well pads classified as producing natural gas (A) or actively being drilled (B) between January 2008 and May 2015 in the high- and low-development winter range study areas in the Piceance Basin, Colorado, USA.

Figure 3. Posterior distributions of population-level coefficients corresponding to the number of well pads within different buffers around deer global positioning system (GPS) locations where active drilling was ongoing. Estimates are for models fit to data from the high-development study area for night and day for the 2008-2009 and 2010 winters. We estimated coefficients using resource selection functions fit to GPS radio-collar data from doe mule deer on winter range in the Piceance Basin, Colorado, USA. Note that the range of $y$-axis values differs by plot.

Figure 4. Posterior distributions of population-level coefficients corresponding to the number of well pads within different distance buffers around deer global positioning system (GPS) locations that were producing natural gas. We obtained estimates using resource selection functions fit to GPS radio-collar data from doe mule deer during winter in the Piceance Basin, Colorado, USA, from winter 2008 and 2009 through winter 2015. We fit models separately for 
each year, daytime and nighttime, and for the low- and high-development study areas. Where estimates are missing (i.e., $200 \mathrm{~m}$ for the low-development area), we did not include covariates in models because too few data points fell within the distance buffer.

Figure 5. Predicted relative probability of selection as a function of the number of producing well pads within $200 \mathrm{~m}$ and the number of drilling well pads within $400 \mathrm{~m}$ (A) and the number of drilling well pads within $400 \mathrm{~m}$ and within 400-600 m (B). We generated estimates using population-level coefficients from resource selection functions fit to global positioning system radio-collar data from doe mule deer during the day during the 2010 winter season in the highdevelopment winter range study area in the Piceance Basin, Colorado, USA. Note that only 1 year is shown as representative examples for simplicity.

Figure 6. Predicted relative probability of selection relative to the distance to natural gas facilities from population-level resource selection functions fit to global positioning system radio-collar data from doe mule deer during winter in the Piceance Basin, Colorado, USA, from winter 2008 and 2009 through winter 2015. We fit models separately for each year, daytime and nighttime, and for the low- and high-development study areas. We show only median estimates.

Figure 7. Predicted relative probability of selection relative to the distance to roads from population-level resource selection functions fit to global positioning system radio-collar data from doe mule deer during winter in the Piceance Basin, Colorado, USA, from winter 2008 and 2009 through winter 2015. We fit models separately for each year, daytime and nighttime, and 
for the low- and high-development study areas. We show only median estimates. Note that the range of $y$-axis values differs by plot.

Figure 8. Predicted relative probability of selection relative to the distance to pipelines from population-level resource selection functions fit to global positioning system radio-collar data from doe mule deer during winter in the Piceance Basin, Colorado, USA, from winter 2008 and 2009 through winter 2015. We fit models separately for each year, daytime and nighttime, and for the low- and high-development study areas. We show only median estimates.

Figure 9. Predicted relative probability of selection relative to a terrain ruggedness index from population-level resource selection functions fit to global positioning system radio-collar data from doe mule deer during winter in the Piceance Basin, Colorado, USA, from winter 2008 and 2009 through winter 2015. We fit models separately for each year, daytime and nighttime, and for the low- and high-development study areas. We show only median estimates. Note that the range of $y$-axis values differs by plot.

Figure 10. Predicted relative probability of selection relative to the distance to treed edges from population-level resource selection functions fit to global positioning system radio-collar data from doe mule deer during winter in the Piceance Basin, Colorado, USA, from winter 2008 and 2009 through winter 2015. We fit models separately for each year, daytime and nighttime, and for the low- and high-development study areas. We show only median estimates. Note that the range of $y$-axis values differs by plot. 
Figure 11. Coefficient estimates for covariates related to land cover classification from population-level resource selection functions fit to global positioning system radio-collar data from doe mule deer during winter in the Piceance Basin, Colorado, USA, from winter 2008 and 2009 through winter 2015. We fit models separately for each year, daytime and nighttime, and for the low- and high-development study areas. We show only median estimates. In all models, the reference category was the land cover class defined as forage.

Figure 12. Predicted relative probability of selection relative to snow depth from populationlevel resource selection functions fit to global positioning system radio-collar data from doe mule deer during winter in the Piceance Basin, Colorado, USA, from winter 2008 and 2009 through winter 2015. We fit models separately for each year, daytime and nighttime, and for the low- and high-development study areas. We show only median estimates. Note that the range of $y$-axis values differs by plot.

Figure 13. Maps of predicted median relative probability of selection calculated from populationlevel coefficients estimated using resource selection functions (RSF) fit to global positioning system radio-collar data from doe mule deer. We fit models separately for each winter from 2008-2009 through 2015 for nighttime and daytime in the low- and high-development winter range study areas in the Piceance Basin, Colorado, USA. We combined data from 2008 and 2009 because of low sample sizes but produced maps for each year separately. We averaged dynamic covariates (i.e., snow depth and development infrastructure locations) across the entire winter season for mapping purposes. Lighter colors indicate higher relative probability of selection. Predicted RSF values have been binned into 10 bins based on quantiles for display purposes 
only. The study area boundaries are shown in white, with the northern study area relating to the low-development area and the southern area the high-development area. The $x$ and $y$ axes represent the X and Y coordinates in meters for North American Datum of 1983 (NAD83) Universal Transverse Mercator zone 12.

Figure 14. Maps of predicted median relative probability of selection calculated from populationlevel coefficients estimated using resource selection functions (RSF) fit to global positioning system radio-collar data from doe mule deer. We fit models separately for each winter from 2008-2009 through 2015 for nighttime and daytime in the high- and low-development winter range study areas in the Piceance Basin, Colorado, USA. We created maps by predicting relative probability of selection across study areas. For each year, we predicted relative probability of selection in the low-development area using the corresponding high-development area model and vice versa, providing an assessment of what habitat selection patterns would look like if deer were moved to the opposite study area and showed invariant behavior. We combined data from 2008 and 2009 because of low sample sizes but produced maps for each year separately. We averaged dynamic covariates (i.e., snow depth and development infrastructure locations) across the entire winter season for mapping purposes. Lighter collars indicate higher relative probability of selection. Predicted RSF values have been binned into 10 bins based on quantiles. The study area boundaries are shown in white, with the northern study area relating to the low-development area and the southern area the high-development area. The $x$ and $y$ axes represent the $\mathrm{X}$ and $\mathrm{Y}$ coordinates in meters for North American Datum of 1983 (NAD83) Universal Transverse Mercator zone 12. 
Figure 15. Median and interquartile range of age of doe mule deer, determined using patterns of tooth eruption and wear between the 2010 and 2015 winter seasons in the low- and highdevelopment winter range study areas in the Piceance Basin, Colorado, USA.

Figure 16. Mean \pm standard deviation percent ingesta-free body fat determined using ultrasonography and palpation of the rump for doe mule deer captured in December (A) and March (B) between March 2009 and December 2015 in the low- and high-development winter range study areas in the Piceance Basin, Colorado, USA. Panel C shows mean \pm standard deviation of December to March change in percent ingesta-free body fat.

Figure 17. Mean \pm standard deviation of pregnancy rate determined using pregnancy-specific protein B (A) and fetal counts determined using ultrasonography (B) for doe mule deer captured in March between 2009 and 2015 in the low- and high-development winter range study areas in the Piceance Basin, Colorado, USA.

Figure 18. Mean \pm standard deviation of male (left panel) and female (right panel) mass for mule deer fawns captured in December between 2009 and 2015 in the low- and high-development winter range study areas in the Piceance Basin, Colorado, USA.

Figure 19. Mean and 95\% confidence limits for model-averaged doe mule deer monthly survival between March 2009 and April 2015, in the low- and high-development winter range study areas in the Piceance Basin, Colorado, USA. 
Figure 20. Mean and 95\% confidence limits for model-averaged fawn mule deer monthly survival between March 2009 and April 2015, in the low- and high-development winter range study areas in the Piceance Basin, Colorado, USA.

Figure 21 . Mean and $95 \%$ confidence limits of mule deer population density estimated from the most parsimonious model according to Akaike's Information Criterion (A) and the post hoc model fit with a random effect on population size (B), with the mean size specified as a linear trend for the 2010 through 2015 winter seasons in the low- and high-development winter range study areas in the Piceance Basin, Colorado, USA. For panel B, estimated mean and 95\% confidence intervals of the trend are shown as solid and dashed lines respectively. 
Table 1. Harvest statistics for the study period for Game Management Unit 22, which encompasses the Piceance Basin of Colorado, USA. Statistics include estimated number of adult male (buck), adult female (doe) and fawn mule deer harvested, and total days hunted by hunters. We obtained data from https://cpw.state.co.us/thingstodo/Pages/Statistics-Deer.aspx (accessed 01 Jan 2016). All hunting took place in the fall of each year.

\begin{tabular}{ccccc}
\hline Year & Bucks harvested & Does harvested & Fawns harvested & Total hunter days \\
\hline 2015 & 404 & 14 & 0 & 3,258 \\
2014 & 413 & 88 & 10 & 3,521 \\
2013 & 436 & 102 & 4 & 3,343 \\
2012 & 358 & 110 & 5 & 2,998 \\
2011 & 457 & 115 & 10 & 3,732 \\
2010 & 404 & 76 & 6 & 3,563 \\
2009 & 390 & 74 & 4 & 3,910 \\
2008 & 401 & 113 & 0 & 4,488 \\
\hline
\end{tabular}


Table 2. Sample sizes of mule deer captured, determined to have died, used in resource selection functions (RSF), and switching between study areas for each winter season and study area (low development [dev] or high development) in the Piceance Basin of Colorado, USA. Also reported are the mean and range of global positioning system locations for individuals used in RSF models in each year. Mortalities are reported as total mortalities from early winter capture through to next year's early winter capture (typically Dec-Dec). We calculated number of deer switching study areas as those that previously had the majority of their kernel density utilization distribution overlapping with one study and in subsequent years had the majority of their kernel density utilization distribution overlapping with the other study area.

\begin{tabular}{|c|c|c|c|c|c|c|c|c|c|}
\hline Winter & Low dev & High dev & Mortalities & Mortalities & Number & Number & Number & Mean & Mean \\
\hline \multirow[t]{4}{*}{ season } & captures early & captures & low dev & high dev & used in & used in & switching & number of & number of \\
\hline & winter / late & early winter & & & RSF low & RSF high & study & relocations & relocations \\
\hline & winter & / late winter & & & dev & dev & areas & (range) & (range) \\
\hline & (recaptures) & (recaptures) & & & & & & low dev & high dev \\
\hline \multirow[t]{2}{*}{$2007-2008$} & $8(0) / 0$ & $7(0) / 0$ & 0 & 0 & 7 & 7 & 0 & 439 (219- & $423(215-$ \\
\hline & & & & & & & & 512) & 508) \\
\hline \multirow[t]{2}{*}{ 2008-2009 } & $0 / 16(1)$ & $0 / 14(1)$ & 0 & 0 & 15 & 13 & 0 & $356(262-$ & $340(238-$ \\
\hline & & & & & & & & 540) & 538) \\
\hline
\end{tabular}




\begin{tabular}{|c|c|c|c|c|c|c|c|c|c|}
\hline 2009-2010 & $21(0) / 11$ & $19(0) / 25$ & 4 & 1 & 33 & 31 & 0 & $361(162-$ & 308 (198- \\
\hline & (9) & (10) & & & & & & 748) & 818) \\
\hline $2011-2012$ & (29) & (28) & & & & & & 826) & 803) \\
\hline 2012-2013 & $29(2) / 29$ & $33(7) / 31$ & 3 & 7 & 51 & 55 & 2 & $670(143-$ & 656 (107- \\
\hline 2013-2014 & (29) & (27) & & & & & & 771) & 753) \\
\hline \multirow[t]{2}{*}{ 2014-2015 } & $29(1) / 28$ & $27(1) / 32$ & 2 & 2 & 21 & 14 & 1 & 705 (606- & $617(151-$ \\
\hline & (26) & (26) & & & & & & 758) & 747) \\
\hline
\end{tabular}


Table 3. Winter season of capture, number of individuals per study area (low development [dev] area or high development) overall and by sex, and number of animals dying between capture and the following June for mule deer fawns captured during December on winter range in the Piceance Basin, Colorado, USA.

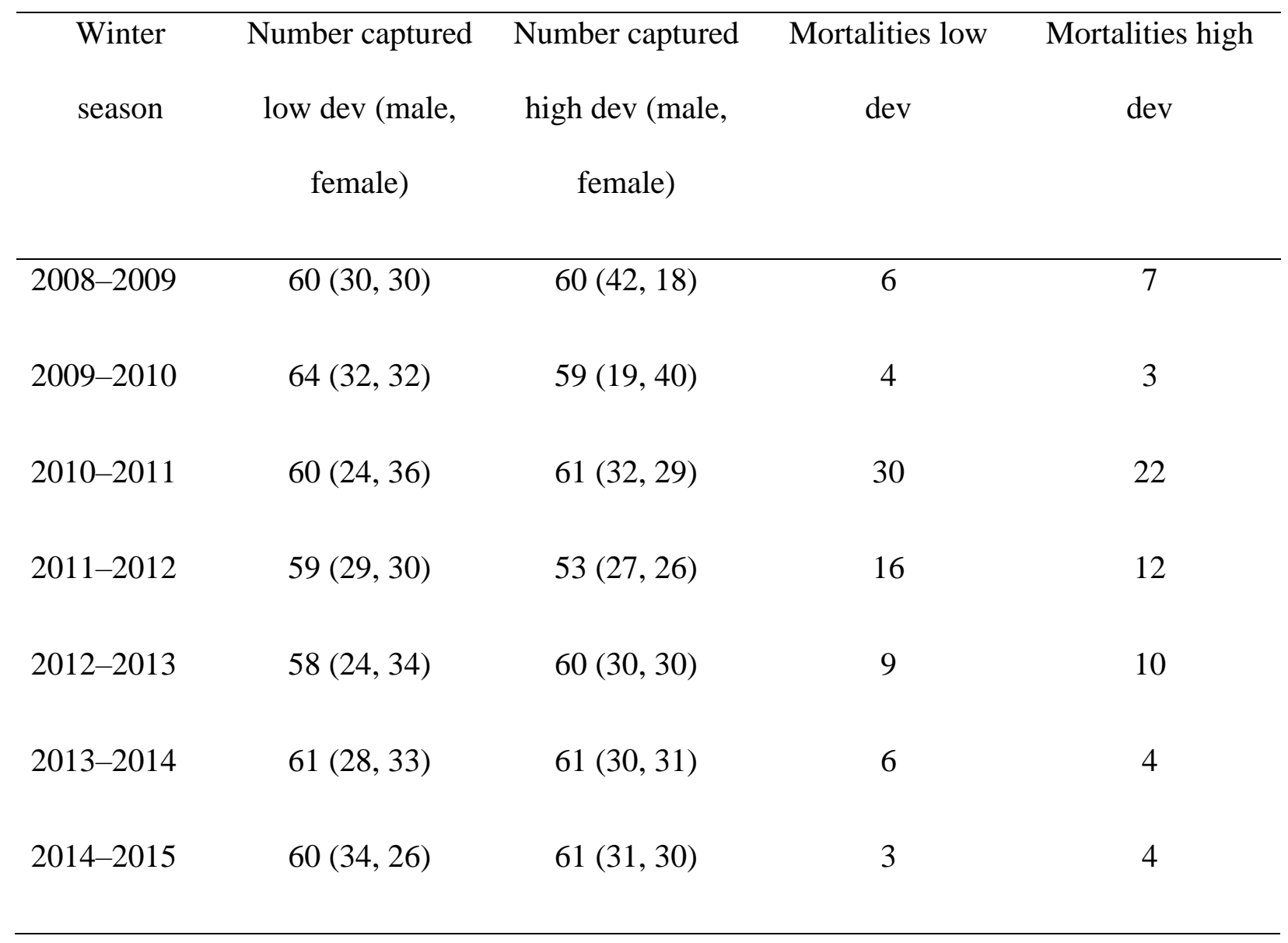


Table 4. Variables used in resource selection function modeling for adult female mule deer in the

Piceance Basin, Colorado, USA, process that we hypothesized they represented (cover, forage, or anthropogenic), description of variable, and the source.

\begin{tabular}{|c|c|c|c|}
\hline Variable & Category & Description & Source \\
\hline $\begin{array}{l}\text { Terrain } \\
\text { ruggedness } \\
\text { index }\end{array}$ & Cover & $\begin{array}{l}\text { The mean difference between the } \\
\text { elevation in a cell and that of the } \\
8 \text { neighboring cells, representing } \\
\text { topographic cover }\end{array}$ & https://earthexplorer.usgs.gov/ \\
\hline Snow depth & Forage & $\begin{array}{l}\text { Daily snow depth derived from a } \\
\text { distributed snow evolution model }\end{array}$ & $\begin{array}{l}\text { (Liston and Elder 2006, Northrup } \\
\text { et al. 2016b) }\end{array}$ \\
\hline Land cover & $\begin{array}{l}\text { Cover and } \\
\text { forage }\end{array}$ & $\begin{array}{l}\text { Categorical variable with land } \\
\text { cover classified as cover, forage, } \\
\text { cover and forage, or sparse }\end{array}$ & $\begin{array}{l}\text { https://www.arcgis.com/home/ } \\
\text { item.html?id= } \\
\text { 893739745fcd4e05af8168b7448cda0c }\end{array}$ \\
\hline $\begin{array}{l}\text { Distance to } \\
\text { edge }\end{array}$ & Cover & $\begin{array}{l}\text { Distance to any edges } \\
\text { representing the transition from } \\
\text { treed land cover to non-treed land } \\
\text { cover }\end{array}$ & $\begin{array}{l}\text { https://www.arcgis.com/home/ } \\
\text { item.html?id= } \\
\text { 893739745fcd4e05af8168b7448cda0c }\end{array}$ \\
\hline $\begin{array}{l}\text { Distance to } \\
\text { road }\end{array}$ & Anthropogenic & Distance to roads & $\begin{array}{l}\text { Digitized from aerial imagery } \\
\text { obtained from the National } \\
\text { Agricultural Imagery Program } \\
\text { https://earthexplorer.usgs.gov/ }\end{array}$ \\
\hline $\begin{array}{l}\text { Distance to } \\
\text { pipeline }\end{array}$ & Anthropogenic & Distance to pipelines & $\begin{array}{l}\text { White River Bureau of Land } \\
\text { Management office and } \\
\text { supplemented from aerial imagery } \\
\text { obtained from the National } \\
\text { Agricultural Imagery Program } \\
\text { https://earthexplorer.usgs.gov/ }\end{array}$ \\
\hline $\begin{array}{l}\text { Distance to } \\
\text { facilities }\end{array}$ & Anthropogenic & Distance to natural gas facilities & $\begin{array}{l}\text { Digitized from aerial imagery } \\
\text { obtained from the National } \\
\text { Agricultural Imagery Program } \\
\text { https://earthexplorer.usgs.gov/ and } \\
\text { validated on the ground }\end{array}$ \\
\hline
\end{tabular}




$\begin{array}{lll}\begin{array}{l}\text { Drilling pads } \\ \text { xxx }\end{array} & \text { Anthropogenic } & \begin{array}{l}\text { Number of well pads classified as } \\ \text { drilling within a given buffer } \\ \text { distance }\end{array} \\ \begin{array}{l}\text { Production } \\ \text { pads xxx }\end{array} \quad \text { Anthropogenic } & \begin{array}{l}\text { Number of well pads classified as } \\ \text { producing within a given buffer } \\ \text { distance }\end{array}\end{array}$


Table 5. Average (SD) of covariates used in resource selection function modeling representing cover and mule deer forage for the low- and high-development study areas in the Piceance Basin, Colorado, USA. Forage, cover, cover and forage, and sparse are categorical covariates and we present the proportion of each study area composed of these categories.

\begin{tabular}{lcc}
\hline \multicolumn{1}{c}{ Covariate } & $\begin{array}{c}\text { Low } \\
\text { development }\end{array}$ & $\begin{array}{c}\text { High } \\
\text { development }\end{array}$ \\
\hline Terrain ruggedness index & $4.95(3.05)$ & $5.00(3.2)$ \\
Elevation (m) & $2,040(115)$ & $2,055(112)$ \\
Distance to edge (m) & $57.5(49.35)$ & $60.6(56.54)$ \\
Forage & 0.33 & 0.35 \\
Cover & 0.23 & 0.22 \\
Cover and forage & 0.36 & 0.33 \\
Sparse & 0.08 & 0.09 \\
\hline
\end{tabular}


Table 6. Average (SD) of daily snow depth layers (m) used in resource selection function modeling for each winter season of the study for the low- and high-development study areas in the Piceance Basin, Colorado, USA.

\begin{tabular}{lcl}
\hline Winter season & $\begin{array}{c}\text { Low } \\
\text { development }\end{array}$ & High development \\
\hline $2007-2008$ & $0.32(0.10)$ & $0.31(0.10)$ \\
$2008-2009$ & $0.09(0.05)$ & $0.08(0.05)$ \\
$2009-2010$ & $0.18(0.06)$ & $0.17(0.06)$ \\
$2010-2011$ & $0.22(0.08)$ & $0.18(0.09)$ \\
$2011-2012$ & $0.12(0.04)$ & $0.11(0.05)$ \\
$2012-2013$ & $0.14(0.07)$ & $0.11(0.07)$ \\
$2013-2014$ & $0.10(0.03)$ & $0.09(0.04)$ \\
$2014-2015$ & $0.05(0.04)$ & $0.04(0.04)$ \\
\hline
\end{tabular}


Table 7. Average (SD) of weekly normalized difference vegetation index layers for MaySeptember of the summer preceding each winter season of the study for the low- and highdevelopment study areas in the Piceance Basin, Colorado, USA.

\begin{tabular}{lcc}
\hline Winter season & $\begin{array}{c}\text { Low } \\
\text { development }\end{array}$ & High development \\
\hline $2007-2008$ & $97.18(51.94)$ & $97.07(51.89)$ \\
$2008-2009$ & $97.28(56.15)$ & $96.73(55.61)$ \\
$2009-2010$ & $96.20(55.78)$ & $95.15(54.99)$ \\
$2010-2011$ & $96.30(53.84)$ & $95.44(53.22)$ \\
$2011-2012$ & $97.35(54.92)$ & $96.44(54.35)$ \\
$2012-2013$ & $92.42(52.65)$ & $91.82(52.37)$ \\
$2013-2014$ & $93.29(52.67)$ & $92.92(52.32)$ \\
$2014-2015$ & $96.30(52.83)$ & $95.61(52.82)$ \\
\hline
\end{tabular}


Table 8. Proportion of each of the high-development (dev) and low-development study areas predicted to be avoided, relative to availability during the day and night for winters 2009 through 2015 from population-level resource selection function models fit to global positioning system radio-collar data from mule deer does in the Piceance Basin, Colorado, USA. Any value < 1 indicated selection less than available (avoidance).

\begin{tabular}{lcccc}
\hline Winter season & Low dev day & Low dev night & High dev day & High dev night \\
\hline 2009 & 0.72 & 0.88 & 0.77 & 0.55 \\
2010 & 0.64 & 0.83 & 0.68 & 0.77 \\
2011 & 0.31 & 0.73 & 0.60 & 0.49 \\
2012 & 0.46 & 0.92 & 0.76 & 0.49 \\
2013 & 0.29 & 0.91 & 0.75 & 0.72 \\
2014 & 0.29 & 0.95 & 0.72 & 0.71 \\
2015 & 0.30 & 0.95 & 0.78 & 0.69 \\
\hline
\end{tabular}


Table 9. Parameters and coefficient estimates for regression models fit to demographic data for mule deer does captured in the Piceance Basin, Colorado, USA between 2009 and 2015.

Coefficients followed by an asterisk (*) indicate $95 \%$ confidence intervals that did not overlap 0 .

We used linear regression for log transformed values of age, Poisson regression for number of fetuses, and logistic regression for lactation status.

\begin{tabular}{|c|c|c|c|}
\hline Covariate & $\mathrm{Age}^{\mathrm{a}}$ & $\begin{array}{l}\text { Number of } \\
\text { fetuses }^{b}\end{array}$ & Lactation status $^{\mathrm{c}}$ \\
\hline Intercept & $1.27^{*}$ & -0.02 & -0.19 \\
\hline 2011 & $0.31^{*}$ & & \\
\hline 2012 & 0.20 & & \\
\hline 2013 & 0.16 & -0.11 & \\
\hline 2014 & 0.25 & -0.09 & 0.54 \\
\hline 2015 & 0.11 & -0.17 & \\
\hline High development & $0.34^{*}$ & 0.09 & -0.50 \\
\hline $2011 \times$ high development & -0.30 & & \\
\hline $2012 \times$ high development & -0.25 & & \\
\hline $2013 \times$ high development & -0.14 & 0.19 & \\
\hline $2014 \times$ high development & -0.20 & 0.21 & -0.003 \\
\hline $2015 \times$ high development & -0.35 & -0.02 & \\
\hline
\end{tabular}




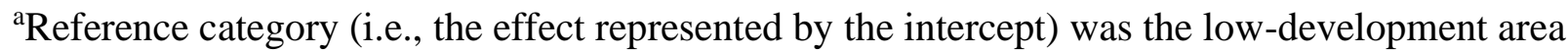
in 2010 .

${ }^{\mathrm{b}}$ Reference category was the low-development area in 2012.

${ }^{\mathrm{c}}$ Reference category the low-development area in 2013. 
Table 10. Covariates and coefficient estimates for regression models fit to condition data for mule deer does captured in the Piceance Basin, Colorado, USA between 2009 and 2015.

Coefficients followed by an asterisk $\left(^{*}\right)$ indicate $95 \%$ confidence intervals that did not overlap 0 .

We used beta regression models in all cases except for overwinter change in fat, where we used a linear regression.

\begin{tabular}{|c|c|c|c|c|}
\hline Covariate & $\begin{array}{l}\text { Early } \\
\text { winter fat }\end{array}$ & $\begin{array}{l}\text { Early winter fat } \\
\text { lactation model }^{\mathrm{b}}\end{array}$ & Late winter fat ${ }^{\mathrm{a}}$ & $\begin{array}{l}\text { Overwinter } \\
\text { change in } \\
\text { fat }^{c}\end{array}$ \\
\hline Intercept & $-1.99 *$ & $-1.97 *$ & $-2.58 *$ & $-5.65^{*}$ \\
\hline 2010 & -0.17 & & 0.07 & \\
\hline 2011 & -0.11 & & -0.05 & 0.30 \\
\hline 2012 & -0.08 & & 0.09 & -0.60 \\
\hline 2013 & -0.11 & & -0.02 & 0.11 \\
\hline 2014 & -0.08 & 0.14 & 0.04 & -0.09 \\
\hline 2015 & & & 0.07 & \\
\hline High development & -0.05 & -0.02 & -0.07 & 0.28 \\
\hline $2010 \times$ high development & 0.15 & & 0.00 & \\
\hline $2011 \times$ high development & 0.01 & & -0.05 & 0.79 \\
\hline $2012 \times$ high development & -0.03 & & -0.02 & 0.32 \\
\hline
\end{tabular}


$2013 \times$ high development

$2014 \times$ high development

$2015 \times$ high development

Lactating

High development lactating

Lactating 2014

High development lactating 2014

Amount of fat in Dec
0.15

0.13

0.05

0.15

$-0.82$

0.08

$-0.34 *$

0.19

$-0.10$

$-0.21$

${ }^{a}$ Reference category (i.e., the effect represented by the intercept) was the low-development area in 2009 .

${ }^{\mathrm{b}}$ Reference category was the low-development area in 2013.

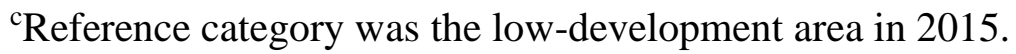


Table 11. Covariates, coefficient estimates, standard errors, and lower and upper $95 \%$ confidence intervals for a gamma regression model fit to mass of fawns captured in December in the Piceance Basin, Colorado, USA, between 2010 and 2015. The reference category (i.e., the effect represented by the intercept) was females in the low-development area in 2015.

\begin{tabular}{|c|c|c|c|c|}
\hline Covariate & Estimate & SE & Lower CI & Upper CI \\
\hline Intercept & 3.59 & 0.02 & 3.5508 & 3.6292 \\
\hline High development & -0.04 & 0.03 & -0.0988 & 0.0188 \\
\hline Male & 0.08 & 0.03 & 0.0212 & 0.1388 \\
\hline 2010 & -0.06 & 0.03 & -0.1188 & -0.0012 \\
\hline 2011 & -0.07 & 0.03 & -0.1288 & -0.0112 \\
\hline 2012 & -0.11 & 0.03 & -0.1688 & -0.0512 \\
\hline 2013 & -0.01 & 0.03 & -0.0688 & 0.0488 \\
\hline 2014 & -0.13 & 0.03 & -0.1888 & -0.0712 \\
\hline High development $\times$ male & 0.01 & 0.04 & -0.0684 & 0.0884 \\
\hline High development $\times 2010$ & 0.02 & 0.04 & -0.0584 & 0.0984 \\
\hline High development $\times 2011$ & -0.005 & 0.04 & -0.0834 & 0.0734 \\
\hline High development $\times 2012$ & 0.03 & 0.04 & -0.0484 & 0.1084 \\
\hline High development $\times 2013$ & 0.02 & 0.04 & -0.0584 & 0.0984 \\
\hline
\end{tabular}




\begin{tabular}{|c|c|c|c|c|}
\hline High development $\times 2014$ & 0.07 & 0.04 & -0.0084 & 0.1484 \\
\hline Male $\times 2010$ & 0.02 & 0.04 & -0.0584 & 0.0984 \\
\hline Male $\times 2011$ & 0.001 & 0.04 & -0.0774 & 0.0794 \\
\hline Male $\times 2012$ & 0.001 & 0.04 & -0.0774 & 0.0794 \\
\hline Male $\times 2013$ & -0.02 & 0.04 & -0.0984 & 0.0584 \\
\hline Male $\times 2014$ & 0.03 & 0.04 & -0.0484 & 0.1084 \\
\hline High development $\times$ male $\times 2010$ & 0.02 & 0.06 & -0.0976 & 0.1376 \\
\hline High development $\times$ male $\times 2011$ & 0.01 & 0.06 & -0.1076 & 0.1276 \\
\hline High development $\times$ male $\times 2012$ & -0.03 & 0.06 & -0.1476 & 0.0876 \\
\hline High development $\times$ male $\times 2013$ & 0.02 & 0.06 & -0.0976 & 0.1376 \\
\hline High development $\times$ male $\times 2014$ & -0.06 & 0.06 & -0.1776 & 0.0576 \\
\hline
\end{tabular}


Table 12. Covariates, coefficient estimates, standard errors, and lower and upper 95\% confidence intervals for the top known-fate survival model fit to data from mule deer does in the Piceance Basin, Colorado, USA from 2009-2015 according to Akaike's Information Criterion corrected for small sample sizes. In this model survival varied by year and season, with an additive effect of study area. Seasons were characterized as winter, summer, and transition, with equivalent survival during fall and spring transition seasons. The reference category was winter 2014-2015 in the high-development area.

\begin{tabular}{lcccr}
\hline Parameter & Estimate & SE & Lower CI & Upper CI \\
\hline Intercept & 5.24 & 0.53 & 4.21 & 6.27 \\
Low development & -0.41 & 0.26 & -0.92 & 0.09 \\
Winter 2009 & 14.87 & 0.00 & 14.87 & 14.87 \\
Transition 2009 & 14.87 & 0.00 & 14.87 & 14.87 \\
Summer 2009 & 18.12 & 0.00 & 18.12 & 18.12 \\
Winter 2009-2010 & 16.95 & 0.00 & 16.95 & 16.95 \\
Transition 2010 & -1.62 & 0.77 & -3.13 & -0.11 \\
Summer 2010 & -0.52 & 0.87 & -2.22 & 1.19 \\
Winter 2010-2011 & -0.49 & 0.67 & -1.81 & 0.83 \\
Transition 2011 & -2.59 & 0.62 & -3.82 & -1.37 \\
Summer 2011 & -1.41 & 0.68 & -2.74 & -0.08 \\
Winter 2011-2012 & -0.88 & 0.62 & -2.09 & 0.32 \\
Transition 2012 & -0.23 & 1.12 & -2.43 & 1.97 \\
Summer 2012 & -1.33 & 0.65 & -2.61 & -0.06 \\
Winter 2012-2013 & -0.04 & 0.71 & -1.43 & 1.35 \\
Transition 2013 & -1.68 & 0.71 & -3.08 & -0.28 \\
Summer 2013 & 0.41 & 1.12 & -1.79 & 2.60 \\
Winter 2013-2014 & -0.74 & 0.62 & -1.95 & 0.47 \\
Transition 2014 & -1.70 & 0.72 & -3.10 & -0.29 \\
Summer 2014 & 0.40 & 1.12 & -1.79 & 2.60 \\
\hline & & & & \\
\hline
\end{tabular}


Table 13. Model structure, Akaike's Information Criterion corrected for small sample sizes $\left(\mathrm{AIC}_{c}\right)$, change in $\mathrm{AIC}_{c}$ values from top model $\left(\triangle \mathrm{AIC}_{c}\right), \mathrm{AIC}_{c}$ weights, and number of parameters $(K)$ for known-fate survival models fit to data from doe mule deer in 2 study areas in the Piceance Basin of Colorado, USA, between 2008 and 2015. Season1 indicates models for which survival during fall and spring migration were equal, and season 2 indicates models for which survival varied between fall and spring migration.

\begin{tabular}{|c|c|c|c|c|}
\hline Model structure & $\mathrm{AIC}_{c}$ & $\Delta \mathrm{AIC}_{c}$ & $\mathrm{AIC}_{c}$ weight & $K$ \\
\hline Season $1 \times$ year + study $^{a}$ & 669.27 & 0.00 & 0.57 & 20 \\
\hline Season $1 \times$ year & 669.89 & 0.62 & 0.42 & 19 \\
\hline Season $1 \times$ year $\times$ study & 678.27 & 9.00 & 0.01 & 26 \\
\hline Season $2 \times$ year + study & 678.66 & 9.39 & 0.01 & 38 \\
\hline Season $2 \times$ year & 679.29 & 10.02 & 0.00 & 25 \\
\hline Season $2 \times$ year $\times$ study & 692.90 & 23.63 & 0.00 & 50 \\
\hline Year $\times$ month + study & 735.90 & 66.63 & 0.00 & 75 \\
\hline Year $\times$ month & 736.54 & 67.27 & 0.00 & 74 \\
\hline Year $\times$ month $\times$ study & 835.93 & 166.66 & 0.00 & 148 \\
\hline
\end{tabular}

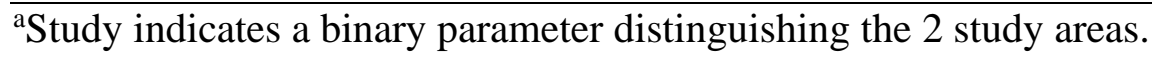


Table 14. Parameters, coefficient estimates, standard errors, and lower and upper 95\% confidence intervals for a known-fate survival model fit to data from mule deer fawns in the Piceance Basin, Colorado, USA, from 2009-2015. In this model survival varied by year. The reference category was 2015.

\begin{tabular}{|c|c|c|c|c|}
\hline Parameter & Estimate & SE & Lower CI & Upper CI \\
\hline Intercept & 4.26 & 0.38 & 3.51 & 5.00 \\
\hline 2009 & -1.86 & 0.48 & -2.79 & -0.92 \\
\hline 2010 & -0.08 & 0.54 & -1.14 & 0.98 \\
\hline 2011 & -2.41 & 0.41 & -3.21 & -1.60 \\
\hline 2012 & -1.60 & 0.43 & -2.44 & -0.76 \\
\hline 2013 & -1.14 & 0.45 & -2.02 & -0.27 \\
\hline 2014 & -0.34 & 0.50 & -1.31 & 0.64 \\
\hline
\end{tabular}


Table 15. Model structure, Akaike's Information Criterion corrected for small sample sizes $\left(\mathrm{AIC}_{c}\right)$, change in $\mathrm{AIC}_{c}$ values from top model $\left(\Delta \mathrm{AIC}_{c}\right), \mathrm{AIC}_{c}$ weights, and number of parameters $(K)$ for known-fate survival models fit to data from fawn mule deer in 2 study areas in the Piceance Basin of Colorado, USA, between 2008 and 2015.

\begin{tabular}{lcccc}
\hline \multicolumn{1}{c}{ Model structure } & $\mathrm{AIC}_{c}$ & $\Delta \mathrm{AIC}_{c}$ & $\mathrm{AIC}_{c}$ weight & $K$ \\
\hline Year & $1,035.46$ & 0.00 & 0.45 & 7 \\
Year + study ${ }^{\mathrm{a}}$ & $1,036.87$ & 1.41 & 0.22 & 8 \\
Year $\times$ month & $1,037.44$ & 1.98 & 0.17 & 35 \\
Year $\times$ month + study & $1,038.86$ & 3.39 & 0.08 & 36 \\
Year + month & $1,039.21$ & 3.75 & 0.07 & 11 \\
Year $\times$ study & $1,045.69$ & 10.23 & 0.00 & 14 \\
Year $\times$ month $\times$ study & $1,074.23$ & 38.77 & 0.00 & 70 \\
Month & & & & \\
\hline
\end{tabular}

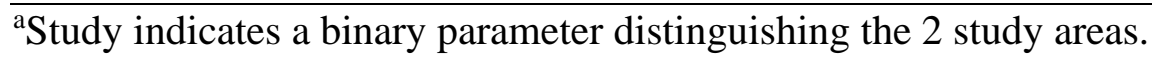


Table 16. Model structures, Akaike's Information Criterion corrected for small sample sizes $\left(\mathrm{AIC}_{c}\right)$, change in $\mathrm{AIC}_{c}$ from top model $\left(\Delta \mathrm{AIC}_{c}\right), \mathrm{AIC}_{c}$ weights, and number of parameters $(K)$ for immigration-emigration logit-normal mixed effects mark-resight models fit to doe mule deer winter range data in the Piceance Basin, Colorado, USA. Models include mean resight probability $(p)$, which was allowed to vary by year and survey or kept constant (.), individual heterogeneity in resighting probability $(\sigma)$, and the difference between the population size within the study area and the super population size using the study area $(\alpha)$.

\begin{tabular}{|c|c|c|c|c|}
\hline Model structure & $K$ & $\mathrm{AIC}_{c}$ & $\Delta \mathrm{AIC}_{c}$ & $\mathrm{AIC}_{c}$ \\
\hline \multicolumn{5}{|l|}{ Low development } \\
\hline$p($ year $\times$ survey $), \sigma \neq 0, \alpha=0$ & 49 & 2,809 & 0.0 & 0.997 \\
\hline$p($ year $\times$ survey $), \sigma=0, \alpha=0$ & 43 & 2,821 & 11.9 & 0.003 \\
\hline$p($ year $\times$ survey $), \sigma \neq 0, \alpha \neq 0$ & 62 & 2,835 & 25.9 & 0.000 \\
\hline$p($ year $\times$ survey $), \sigma=0, \alpha \neq 0$ & 56 & 2,847 & 37.7 & 0.000 \\
\hline$p(),. \sigma \neq 0, \alpha=0$ & 30 & 3,121 & 311.8 & 0.000 \\
\hline$p(),. \sigma=0, \alpha=0$ & 24 & 3,134 & 324.8 & 0.000 \\
\hline
\end{tabular}

High development

$\begin{array}{lllll}p(\text { year } \times \text { survey }), \sigma=0, \alpha=0 & 43 & 2,883 & 0.0 & 0.967\end{array}$ 


$\begin{array}{lcccc}p(\text { year } \times \text { survey }), \sigma \neq 0, \alpha=0 & 49 & 2,890 & 6.7 & 0.033 \\ p(\text { year } \times \text { survey }), \sigma=0, \alpha \neq 0 & 56 & 2,907 & 24.6 & 0.000 \\ p(\text { year } \times \text { survey }), \sigma \neq 0, \alpha \neq 0 & 62 & 2,914 & 31.5 & 0.000 \\ p(.), \sigma=0, \alpha=0 & 24 & 3,135 & 252.6 & 0.000 \\ p(.), \sigma \neq 0, \alpha=0 & 30 & 3,142 & 258.9 & 0.000\end{array}$




\section{SUMMARY OF CONCLUSIONS AND MANAGEMENT IMPLICATIONS}

Adult female mule deer showed substantial behavioral plasticity in the face of natural gas development, with no apparent demographic consequences. Topographically diverse winter range with adequate vegetation providing sufficient food and cover allow deer to alter behavior in an adaptive manner, and similar features should be considered in future development planning. 